\title{
Individual-Level Cognitive and Personality Predictors of Ideological Worldviews: The Psychological Profiles of Political, Nationalistic, Dogmatic, Religious, and Extreme Believers
}

\author{
Leor Zmigrod $^{1}$
}

\author{
${ }^{1}$ Department of Psychology, University of Cambridge, Downing Street, Cambridge, CB2 \\ 3EB, United Kingdom. Lz343@cam.ac.uk.
}

This paper is currently under review. It can be cited as:

Zmigrod, L. (under review). Individual-Level Cognitive and Personality Predictors of Ideological Worldviews: The Psychological Profiles of Political, Nationalistic, Dogmatic, Religious, and Extreme Believers. DOI: 10.31234/osf.io/srgup

\begin{abstract}
Why are some brains more easily gripped by ideological doctrines than others? An emerging research program on the psychological underpinnings of ideological thinking suggests that domain-general individual differences in perception, cognition, and personality can predict people's ideological orientations. Traditionally, the relationship between ideological attitudes and psychological attributes was primarily assessed in the domains of cognitive ability, selfreported cognitive style, or the Big Five personality attributes. Yet a new wave of cognitive and computational research indicates that the tools of cognitive psychology and neuroscience can be harnessed to measure a wider range of individual differences, including cognitive and perceptual traits on flexibility, caution, inhibition, working memory, and sensory evidence accumulation. This review systematically synthesizes theory-driven and data-driven research on the psychological profiles of ideological worldviews including ideological extremism, dogmatism, political conservatism, nationalism, patriotism, religiosity, authoritarianism, system justification, and social dominance orientation. Summaries of the individual-level
\end{abstract}


cognitive and personality predictors of over a dozen ideological orientations are outlined, and core psychological similarities and differences between these ideologies are compared and discussed. The review depicts subtle nuances between the psychological profiles of interrelated ideologies as well as common cognitive, affective, and personality signatures that underpin ideological thinking regardless of the mission of the ideology. The findings illustrate that individual differences in low-level psychophysical perceptual traits shape the dogmatism, extremity, and substance of individuals' ideological beliefs. Addressing pertinent debates in the field, the results depict clear differences in the psychological profiles of dogmatic and conservative ideologies. Consequently, expanding the conceptual and methodological vocabulary with which cognitive dispositions are linked to ideological worldviews is a critical step in widening and deepening our theories on the origins and consequences of ideological thinking - as well as what makes some minds particularly susceptible to adopting particular ideologies.

Keywords: Political psychology; personality; political cognition; conservatism; nationalism; extremism; ideology; ideological thinking; dogmatism; religiosity; system justification; social dominance; intellectual humility; authoritarianism; patriotism; computational social science; drift-diffusion modelling. 
“A person's prejudice is unlikely to be merely a specific attitude toward a specific group; it is more likely to be a reflection of his [or her] whole habit of thinking about the world."

- Gordon Allport, The Nature of Prejudice (1954)

"A deep and penetrating study of individuals may often tell us more about the themes of a contemporary society than will a surface description of the existing institutions... In countries where totalitarianism is a pervasive form of enforced organization, the importance of psychological factors involved in the choice of ideology is greatly reduced, for only when the existing institution leaves room for genuine preference do psychological and sociological factors become important... In a society in which alternative ideologies are offered, a prediction, from psychological data, of such social and political beliefs as liberalism or totalitarianism seems to offer good chances of success."

- Else Frenkel-Brunswik, "Interaction of Psychological and Sociological Factors in Political Behavior" (1952) 


\section{Ideological Minds: Substance versus Structure}

The traumas of totalitarianism cast a long shadow over social and personality psychology in ways that may have once seemed excessive, and yet today appear prophetic. Two insights crystallized: firstly, ideologies are not only located in the external social sphere - the marketplace of ideas - ideologies can infiltrate the minds of adherents in global and totalizing ways. The psychological reverberations of ideologies can manifest even in neutral non-political perception, decision-making, and habits (Frenkel-Brunswik, 1949), demonstrating the depth of ideologies' reach. At the same time, individuals' ideological allegiances can change with the erection of national borders or historical shifts or heightened anxieties, and so we need to be attuned not only to the substance of people's ideological beliefs but also to the structure - the extremity, intolerance, and parochialism - of their ideologies (Zmigrod, 2022).

'Ideology' is a highly contested term in psychology, political science, sociology, and philosophy, and has been endlessly used, misused, and abused (Billig, 1991; Jost, 2006; Jost, Nosek, \& Gosling, 2008; Kalmoe, 2020). The psychological study of ideology has traditionally emphasized the substance of ideological beliefs, guided by questions about what people believe, such as why people believe in omniscient gods or fascist worldviews or the value of social hierarchies (Zmigrod, 2022). This theoretical focus has led to siloed subdisciplines separately dealing with political, religious, moral, and prejudiced attitudes, with few studies evaluating the psychological correlates of multiple ideologies in tandem. The substance-based fractionation has fostered a neglect of the cognitive structure of ideological worldviews and associated questions about why ideologies - in all their forms - so easily grip the human mind, as well as why some minds are more easily gripped by ideologies in general, or some ideologies in particular. 
Yet it is essential to consider the nature of ideological cognition across a multitude of ideologies in order to isolate instances when the mission and substance of the ideology is psychologically-relevant from cases when we ought to focus on the dogmatism and intolerance of ideological thought, regardless of the specific adopted ideology. As a result, a new emerging research program has sought to investigate the psychological underpinnings of several ideological worldviews simultaneously, and thereby to map the individual-level cognitive and personality predictors of ideological thinking generally as well as the unique features of certain ideological worldviews specifically (Zmigrod, 2020, 2021, 2022; Zmigrod et al., 2021).

One tension in the field has been between accounts of ideological behaviour that stress the situation-based versus the person-based origins of ideologically-motivated thought and action (Hodson \& Dhont, 2015; Kahle, 1984; Zmigrod, 2021). Situational theories have typically suggested that strong situations or environments that invite authoritarianism, conformity, or violence, amplify our general human biases towards authoritarianism, conformity, or violence, and so provoke ideologically-motivated behaviour (Figure 1). Ideological doctrines thus unilaterally impose themselves on human minds, with little capacity to resist or respond. In caricatures of situation-based theories, individual differences are largely unimportant, and the mental computations that take place in the minds of ideological followers and fanatics are largely uninteresting or impractical to investigate (a "black box", if you will). The earliest sparks of social and personality psychology, from the landmark studies by Migram (1963), Asch (1956), Festinger (1956), and Sherif (1936), emphasized such "strong situations" as they sought to explain why individuals obey, conform, or commit harm in contexts of (implicit or explicit) ideological coercion, even in novel or minimal-group contexts. A situational flavour is also implicit in sociological or political scientific theories that centre on how environmental socialization dictates the formation of political beliefs (Campbell et al., 1960; Hyman, 1959; Zaller, 1992) - echoing the notion that the mind is a "mindless" (Arendt, 
1951) blank slate susceptible to the imprints of ideological doctrines and pressures, with little individual variation or complex mental processes.

A different emphasis is made by person-based accounts, which underscore the role of personal factors in shaping ideological engagement. Traditionally, person-based theories of ideological behaviour are fundamentally motivational theories (Adorno et al., 1950; Allport, 1954; Dember, 1974; Duckitt \& Sibley, 2009, 2010; Greenberg, Solomon, \& Pyszczynski, 1997; Janoff-Bulman, 2009; Jost, 2017; Jost et al., 2003; Jost, Napier, Thorisdottir, et al., 2007; Hennes, Nam, Stern, \& Jost, 2012; Molden, Bayes, Druckman, 2021; Norenzayan \& Gervais, 2013; Rokeach, 1960; Walker, 1983; Webber \& Kruglanski, 2018), arguing that all humans have basic epistemic, relational, and existential needs to experience a coherent, connected, and comforting world, and these motivations guide our selection and adherence to ideological worldviews. Some situations may elicit stronger needs or amplify the awareness of unfulfilled needs, and so people will accordingly behave in ways that generate or protect a sense of a secure, shared reality. There is room for individual differences: both chronically and temporarily, some individuals may experience these psychological motivations to a greater degree than others. In contrast to situational theories that highlight how ideological doctrines impose themselves on human minds, motivational person-based theories stress why human minds might be pulled towards ideological doctrines to satisfy psychological needs (Figure 1).

Nevertheless, while the situation-based models emphasize "push" factors and the motivational person-based models underline "pull" factors, there is something incomplete in both accounts. Conceptually and methodologically, fixating on motivations ignores the cognitive and neuroscientific revolutions in psychology which have illustrated that implicit and objective measures of neurocognition are often discordant with self-reported measures of traits and behaviour (e.g. Enkavi, Eisenberg, et al., 2019; Saunders et al., 2018; Van Hiel et al., 2016; Wennerhold, Friese, \& Vazire, 2020). Assessing cognitive traits directly with objective 
behavioural measures is essential for crafting a comprehensive cognitive science of ideological thought and action. With an evermore sophisticated understanding of how brains respond to environments, an exclusive attention to self-reported motivations or artificially-created situations - and an assumption that these have unilateral relationships with human minds seems unfinished and oversimplistic. There is thus a need to (1) elaborate on the psychological roots of ideologies beyond motivations and (2) address the complex bilateral relationships between ideological environments and psychological dispositions.

Furthermore, meta-scientifically, theorising about motivations can be an inherently circular and vicious process for political and personality psychologists. Generating hypotheses about the origins and consequences of ideologies might easily be an instance of motivated reasoning itself. When defining and framing the psychological needs that are most pertinent to political cognition, we can risk excessively relying on scientists' imagination, intuitions, and ideological preferences, and so we need conceptual and methodological safeguards against an ideologically-motivated science of ideologies (for a different perspective, see Jost, 2017). Even if one is inclined to dismiss these worries on the politicization of political psychology, it still seems desirable to build a science impervious to concerns about researchers' motivations and the limits or biases of their (scientific) imaginations.

A more comprehensive and nuanced model is thus needed to address the question: what is the relationship between ideological doctrines and the minds of adherents? A proliferation of research over the past five years employing cognitive, genetic, and neuroscientific methodologies to study the individual differences that underpin ideological dogmatism and attitudes has made room for an alternative framework that integrates contemporary understandings of the brain with the foundational questions of personality psychology. This Neurocognitive Model of Ideological Thinking proposes that we can place neurocognition at the centre of what makes an individual susceptible to ideological thought and action - and 
subsequently integrate the modulating influences of situations, environments, and motivations on the human mind.

\section{The Neurocognitive Model of Ideological Thinking}

The Neurocognitive Model of Ideological Thinking argues that ideological worldviews may be manifestations of individuals' perceptual and cognitive systems (Zmigrod, 2021). The Neurocognitive Model makes two essential claims. Firstly, there are neurocognitive antecedents to ideological thinking: the brain's low-level neurocognitive dispositions influence its receptivity to ideological doctrines. And secondly, there are neurocognitive consequences to ideological engagement: strong exposure and adherence to ideological doctrines can shape perceptual and cognitive systems. There are bidirectional relationships between an individual's neurocognitive tendencies and the ideologies they adopt, adhere to, or reject. Human beings differ in their susceptibility to ideologies, at least in part, due to variation in neurocognition and both chronic and temporary experiences modulate the relationship between neurocognition and ideological behaviour. The Neurocognitive Model can provide a framework through which to (a) understand empirical findings from the literature, (b) to postulate casual mechanisms, and (c) evaluate how neurocognition interacts with situational and motivational factors in determining ideological beliefs and behaviour (Zmigrod, 2021). 

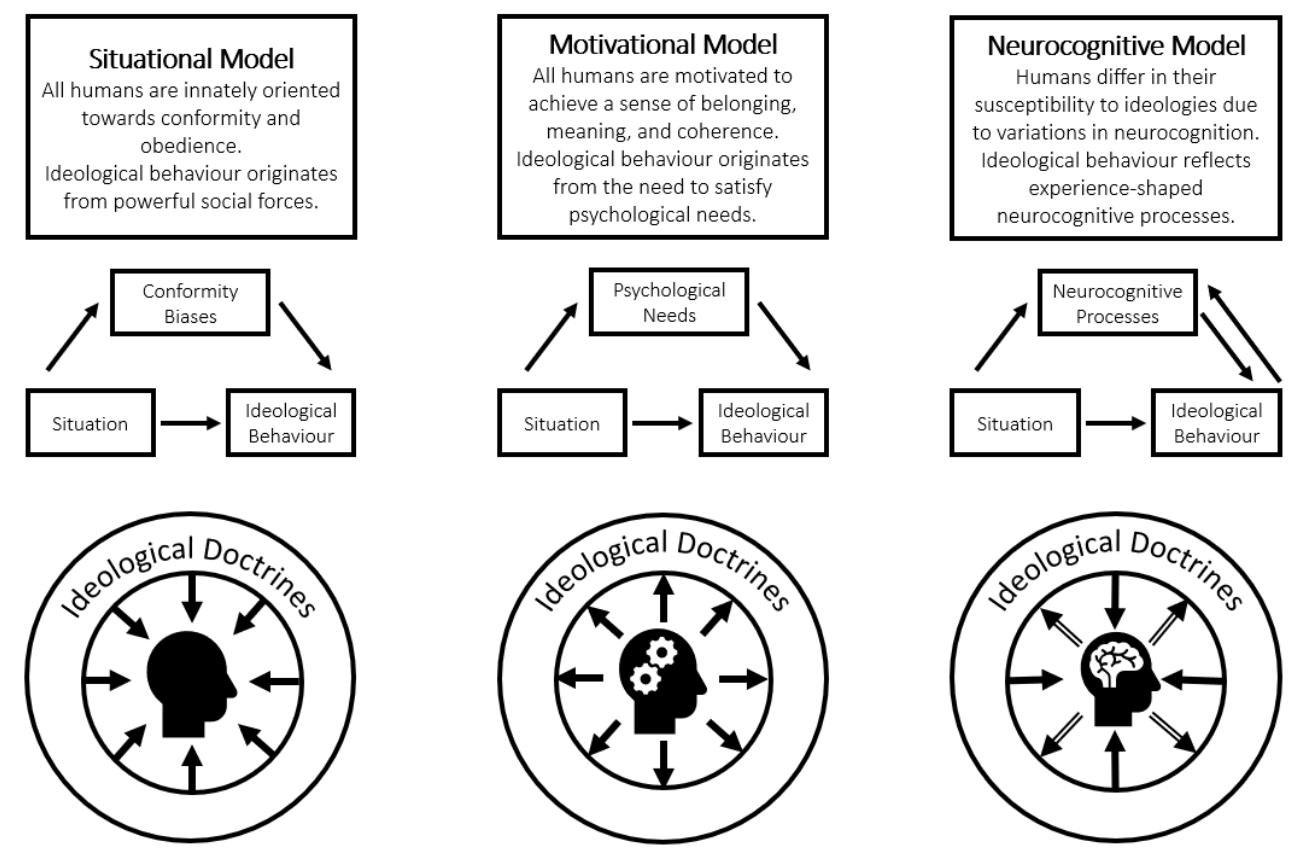

Figure 1. Summaries of the premises, assumptions, and essential causal relations posited by the (A) situational model, (B) motivational model, and (C) neurocognitive model of ideological behavior. Each model gives a different weight to the role of the mind and brain in shaping ideological attitudes (increasing from left to right), and each model makes different assumptions about how external situations shape ideological behavior. Reproduced from Zmigrod (2021).

The Neurocognitive Model of Ideological Thinking (Zmigrod, 2021) was born out of a series of empirical studies that have sought to map the person-based characteristics that promote ideological thinking in political, nationalistic, religious, and social domains. In the following sections, the review will summarize and synthesize the empirically- and computationally-derived psychological profiles of a series of ideological worldviews, and situate these within contemporary social and personality psychological theory. In trying to identify what makes a mind 'ideological', this research program seeks to tap into how humans' perceptual apparatus - how they process shapes and information at the lowest perceptual level - can shed light on their social and political beliefs. It is thus an endeavour that uses approaches from experimental psychology and individual differences research to unpack an overtly social phenomenon. Although it begins with the individual and the comparison of individuals, it has 
the potential to inform social and intergroup dynamics that are of pertinent interest to personality psychologists.

\section{The Cognitive and Personality Signatures of Ideological Worldviews}

There are two primary approaches for mapping out the cognitive and personality underpinnings of ideological orientations: theory-driven approaches and data-driven approaches. Theory-driven research involves generation of specific hypotheses which are then directly tested by designing experimental paradigms that will corroborate or falsify the hypotheses. Theory-driven approaches are therefore top-down, allowing researchers' theorical assumptions and expectations to guide data collection and analysis. In contrast, data-driven research consists of rich datasets which are systematically and principledly analysed in order to arrive at broader theoretical generalizations. Data-driven approaches are thus bottom-up, moving from empirical observations towards the formation of theoretical inferences and hypotheses. In social and political psychology, complementing theory-driven research with data-driven approaches has the advantage of ensuring that theories of ideological thinking are not too heavily skewed by researchers' own ideologies (Duarte et al., 2015; Malka, Lelkes, \& Holzer, 2017; Reinero et al., 2020; Tetlock, 1994; Washburn \& Skitka, 2018) and facilitating a comprehensive and cumulative science (Zmigrod, 2022).

One of the most recurrent theoretically-driven debates in political psychology concerns the question of whether there is a rigidity-of-the-right effect, whereby political conservatives are more cognitively rigid than political liberals, or whether there is a rigidity-of-the-extreme effect, in which ideologues on both the political left and right are more rigid than their moderate counterparts (Jost et al., 2003; Jost, 2017; Van Hiel et al., 2016; Zmigrod, 2020). Methodologically, this debate has been obfuscated by the fact that a majority of studies employ self-reported questionnaires as a way to tap into "cognitive rigidity" or cognitive style rather 
than using objective cognitive assessments. Neuropsychological tasks that measure cognitive flexibility generally involve neutral visual or linguistic stimuli and require participants to adapt their behaviour to repeatedly-changing reward contingencies or to be able to generate new ideas or semantic associations flexibly (Zmigrod, 2020). Yet an overwhelming number of studies probing cognitive flexibility in social and personality psychology in fact depend on self-report measures (e.g. Buechner et al., 2020). In Jost's (2017) extensive review and meta-analysis, 16 studies were identified that investigated the rigidity-of-the-right hypothesis, yet out of the nine studies which supported the rigidity-of-the-right effect, six studies used a self-report measure of cognitive rigidity. A meta-analysis by Van Hiel and colleagues (2016) illustrated that the relationship between cognitive rigidity and political conservatism was amplified when studies relied on self-report questionnaires of rigidity as opposed to behavioural measures, highlighting the importance of multidimensional assessment methods. Resolution to the dispute has also been clouded by the fact that extremism or dogmatism are rarely directly measured and instead are typically inferred from measures of political conservatism. Problematically, many researchers take participants who rate themselves as "strongly liberal" and "strongly conservative" as necessarily extreme, thus confounding the substance of an ideology with the degree to which it is held dogmatically (Zmigrod, 2020, 2021, 2022).

When a series of cognitive behavioural measures were used to assess mental flexibility, and political conservatism was disentangled from political extremity, dogmatism, or partisanship, a clear inverted-U shaped curve emerged such that those on the extreme right and extreme left exhibited cognitive rigidity on neuropsychological tasks, in comparison to moderates (Figure 2; Zmigrod, Rentfrow, \& Robbins, 2020). Behavioural measures generally support a rigidity-of-the-extreme effect (Zmigrod, 2020). Nonetheless, there may still be a rigidity-of-the-right effect on top of the rigidity-of-the-extreme effect, as observed by the shift of the inverted-U shaped curve's centre to the left-of-centre (Zmigrod, Rentfrow, \& Robbins, 
2020; Figure 2). Indeed cognitive rigidity on neuropsychological tasks such as the Wisconsin Card Sorting Test and Remote Associates Test, has also been linked to political conservatism and adjacent constructs such as nationalism and authoritarianism (Zmigrod et al., 2018). The field therefore needs to make room for the merit in both the rigidity-of-the-right and rigidityof-the-extreme hypotheses and to exhibit care in the measurement of cognition and ideology in order to isolate the underlying mechanisms.
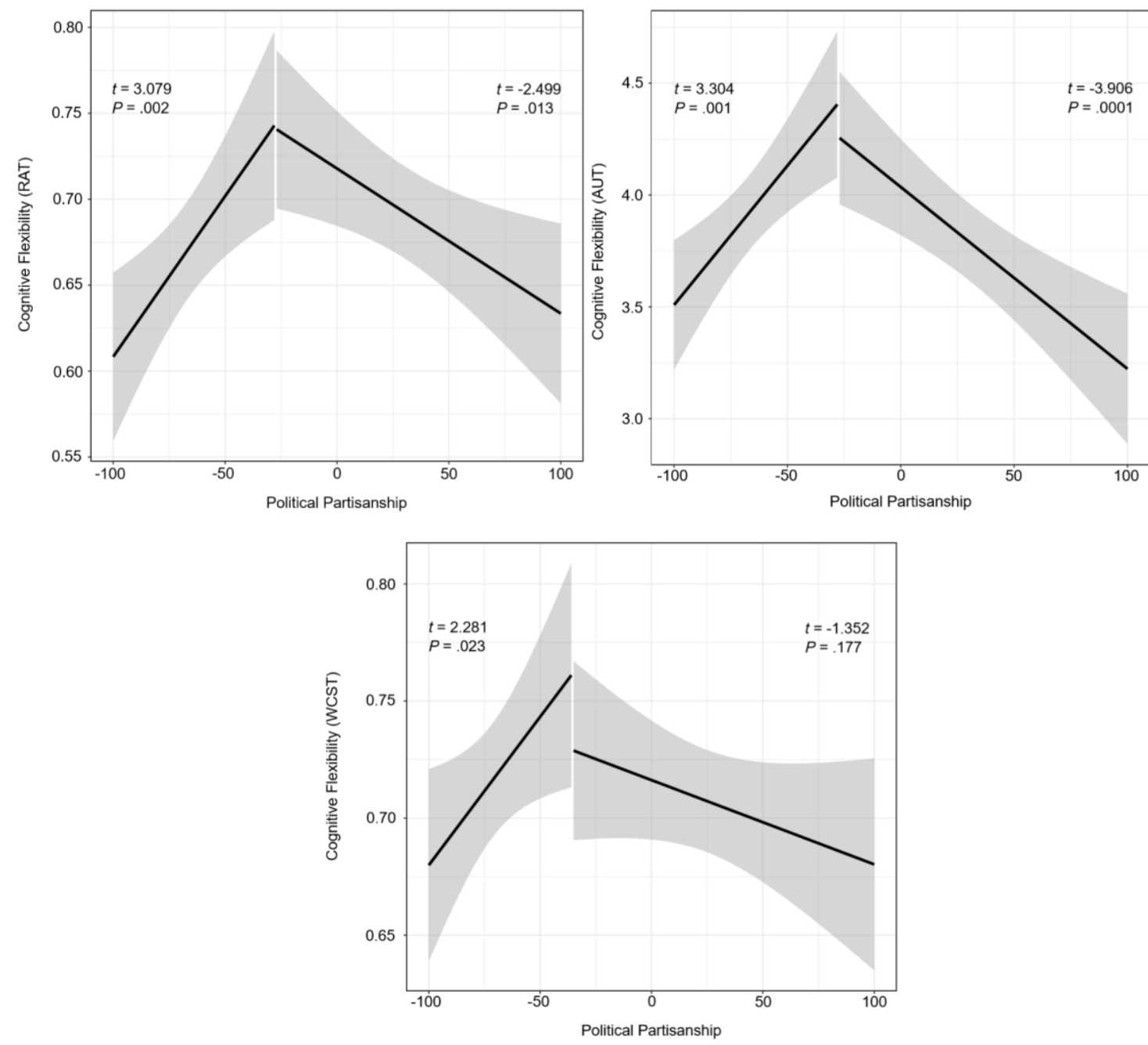

Figure 2. Inverted-U-shaped curves depicting cognitive flexibility for participants ranging from strongly partisan to the Democratic Party to those strongly partisan for the Republican Party (N=743) across three measures of cognitive flexibility. The shaded area reflects 95\% confidence intervals. Reprinted with permission from Zmigrod, Rentfrow, \& Robbins (2020). RAT=Remote Associates Test. AUT=Alternative Uses Test (Flexibility index). WCST $=$ Wisconsin Card Sorting Test. 
The fierce debate between those advocating a rigidity-of-the-right framework (Jost et al., 2003; Jost, 2017) versus those in favour of a rigidity-of-the-extreme perspective (e.g. Crawford \& Pilanski, 2014) exemplifies one of the core challenges in mapping out the cognitive and personality underpinnings of ideological thinking: many political psychologists still disagree on what it means to measure individual differences in "cognitive" processes. Methods from cognitive psychology are rarely consulted or implemented, and so political psychological studies primarily consider the relationships between ideology and cognitive ability (essentially equivalent to general intelligence; Dhont \& Hodson, 2014; Hodson \& Busseri, 2012; Ludeke, Rasmussen, \& DeYoung, 2017; Onraet et al., 2015) or cognitive style (measured with self-report assessments of need for cognition or cognitive closure or a brief measure of analytical reasoning, the Cognitive Reflections Test; Ksiazkiewicz, Ludeke, \& Krueger, 2016; Yilmaz \& Saribay, 2017). While cognitive ability and cognitive style have been useful anchors for building a psychological science of ideology and prejudice, cognitive psychology offers a much broader set of individual difference measures and constructs. Consequently, it is helpful to turn to cognitive scientific methods that measure a range of cognitive traits, including flexibility, inhibition, working memory, and perceptual dispositions. In a recent large-scale data-driven study, a battery of over 37 cognitive tasks and 22 personality surveys were administered two years prior to the collection of participants' ideological attitudes (Zmigrod et al., 2021). Sixteen ideological worldviews were tested, including participants' dogmatism, social and economic conservatism, nationalism, social dominance orientation, system justification, authoritarianism, religiosity, and more. By virtue of this rich dataset, for the first time, it has become possible to map out the cognitive and personality predictors of a range of ideological worldviews in tandem, using a data-driven and computational approach. The results of the data-driven analysis reveal unique signatures for different ideological worldviews as well as commonalities across them - highlighting what it means to be 
"ideological" as well as what it means to be ideological in specific domains. The following sections will outline empirical work on the cognitive, perceptual, and personality signatures of a series of ideological orientations, clustered broadly into (1) dogmatic tendencies, (2) political ideologies, and (3) religious ideologies. Situating these empirical fingerprints within contemporary social psychological theories should therefore elucidate the cognitive and personality underpinnings of these ideological orientations as well as pose new experimental and theoretical questions.

\section{Dogmatism and Intellectual Humility:}

A core component of being "ideological" is dogmatism: a closed-mindedness reflected in the steadfast belief that one's own viewpoints are the only correct and acceptable opinions, and that a plurality of perspectives is dangerous and undesirable (Rokeach, 1960; Shearman \& Levine, 2006). Dogmatic individuals tend to avoid inconsistent or contradictory information (Kleck \& Wheaton, 1967; Palmer \& Klain, 1985) and generally feel threatened by diversity, difference, or complexity. A related construct, intellectual humility - the conceptual inverse of dogmatism - taps into an individual's acknowledgement that one's knowledge and abilities are limited and fallible (Krumrei-Mancuso \& Rouse, 2016). An intellectually humble person is thus open to updating their beliefs in light of persuasive ideas and credible evidence, attaining the right balance between avoiding rigid dogmatism on one hand and changing beliefs too quickly in light of alternative arguments on the other (Krumrei-Mancuso \& Rouse, 2016; Krumrei-Mancuso \& Newman, 2020; Leary et al., 2017; Porter \& Schumann, 2018). In line with Krumrei-Mancuso and Rouse's (2016) Comprehensive Intellectual Humility Scale, it is fruitful to decompose intellectual humility into four constituent facets, including: (1) independence of intellect and ego, capturing an individual's capacity to debate perspectives without feeling or causing hurt, (2) openness to belief updating, reflecting an individual's receptivity to revising their viewpoints in light of new and credible information, (3) respect for 
others' beliefs, signalling an individual's willingness to engage with people they disagree with, and (4) lack of intellectual overconfidence, depicting an individual's awareness that their intellectual capacities may be limited and so listening to others' expertise can be a valuable exercise. Intellectual humility thus captures an individual's receptivity to evidence-based belief updating, which is diametrically opposed to ideological and doctrinal thinking that is impervious to change or challenge (Zmigrod, 2022). Dogmatism, or lack of intellectual humility, is high in political conservatives as well as in those who are ideologically extreme on either the political left or political right (Toner et al., 2013; Harris \& Van Bavel, 2021). It is therefore valuable to investigate the psychological traits of dogmatic individuals, examining the roots of dogmatism separately from the correlates of other political ideologies.

What are the cognitive characteristics of the dogmatic mind? A series of studies employing methodologies from cognitive psychology have recently examined the relationships between dogmatic tendencies and individual differences in perceptual and cognitive traits, as measured with neuropsychological tasks (Zmigrod et al., 2019, 2021). These neuropsychological tasks assess participants' performance on timed decision-making tasks using neutral visual or linguistic stimuli. By using experimental paradigms borrowed from neuropsychology and psychophysics, it becomes possible to identify the low-level cognitive tendencies that sculpt the nature of high-level ideological attitudes and orientations.

The findings on the cognitive roots of dogmatism demonstrate that it is tied to cognitive rigidity, while intellectual humility is associated with cognitive flexibility on neuropsychological tasks (Zmigrod et al., 2019). Cognitive flexibility and intelligence were specifically related to the facets of intellectual humility concerned with heightened receptivity towards updating one's beliefs in response to evidence and tolerance for alternative perspectives (Zmigrod et al., 2019). These cognitive traits may therefore underpin the capacity to be intellectually humble and non-ideological. 
Table 1. Summary of results on cognitive and personality correlates of dogmatism and intellectual humility.

\begin{tabular}{|c|c|c|c|}
\hline & Example Items & Cognitive Traits & Personality Traits \\
\hline Dogmatism & $\begin{array}{l}\text { "There is a single } \\
\text { correct way to do } \\
\text { most things"1 }\end{array}$ & $\begin{array}{l}\text { Cognitive rigidity }{ }^{3} \\
\text { Slow sensory evidence } \\
\text { accumulation }\end{array}$ & $\begin{array}{l}\text { High impulsivity } \\
\text { Low social risk-taking }\end{array}$ \\
\hline $\begin{array}{l}\text { Intellectual } \\
\text { Humility Facet } \\
\# 1: \text { Independence } \\
\text { of Intellect and } \\
\text { Ego }\end{array}$ & $\begin{array}{l}\text { "I tend to feel } \\
\text { threatened when } \\
\text { others disagree } \\
\text { with me on topics } \\
\text { that are close to } \\
\text { my heart"2 }\end{array}$ & $\begin{array}{l}\text { Fast sensory evidence } \\
\text { accumulation }\end{array}$ & $\begin{array}{l}\text { High emotional control } \\
\text { High social risk-taking } \\
\text { Low ethical risk-taking } \\
\text { Low risk perception }\end{array}$ \\
\hline $\begin{array}{l}\text { Intellectual } \\
\text { Humility Facet } \\
\text { \#2: Openness to } \\
\text { Belief Updating }\end{array}$ & $\begin{array}{l}\text { "I am open to } \\
\text { revising my } \\
\text { important beliefs } \\
\text { in the face of new } \\
\text { information"2 }\end{array}$ & $\begin{array}{l}\text { Cognitive flexibility }^{3} \\
\text { Intelligence }^{3} \\
\text { Fast sensory evidence } \\
\text { accumulation } \\
\text { Low temporal } \\
\text { discounting }\end{array}$ & $\begin{array}{l}\text { Low impulsivity } \\
\text { High social risk-taking } \\
\text { Low ethical risk-taking } \\
\text { Low mindfulness }\end{array}$ \\
\hline $\begin{array}{l}\text { Intellectual } \\
\text { Humility Facet } \\
\text { \#3: Respect for } \\
\text { Others' Beliefs }\end{array}$ & $\begin{array}{l}\text { "I welcome } \\
\text { different ways of } \\
\text { thinking about } \\
\text { important topics"2 }\end{array}$ & $\begin{array}{l}\text { Cognitive flexibility } \\
\text { Intelligence } \\
\text { Fast sensory evidence } \\
\text { accumulation }\end{array}$ & $\begin{array}{l}\text { Low impulsivity } \\
\text { High social risk-taking } \\
\text { Low ethical risk-taking } \\
\text { High reward sensitivity } \\
\text { High agreeableness }\end{array}$ \\
\hline $\begin{array}{l}\text { Intellectual } \\
\text { Humility Facet } \\
\text { \#4: Lack of } \\
\text { Intellectual } \\
\text { Overconfidence }\end{array}$ & $\begin{array}{l}\text { "My ideas are } \\
\text { usually better } \\
\text { than other } \\
\text { people's ideas"2 }\end{array}$ & & $\begin{array}{l}\text { High social risk-taking } \\
\text { Low reward sensitivity } \\
\text { High agreeableness } \\
\text { Low ethical risk-taking }\end{array}$ \\
\hline $\begin{array}{l}\text { Dogmatism } \\
\text { Factor }\end{array}$ & $\begin{array}{l}\text { Scores from } \\
\text { factor analysis } \\
\text { including five } \\
\text { sub-scales above }\end{array}$ & $\begin{array}{l}\text { Slow sensory evidence } \\
\text { accumulation }\end{array}$ & $\begin{array}{l}\text { High impulsivity } \\
\text { High ethical risk-taking } \\
\text { Low social risk-taking } \\
\text { Low agreeableness }\end{array}$ \\
\hline
\end{tabular}

${ }^{1}$ Shearman \& Levine, 2006; ${ }^{2}$ Krumrei-Mancuso \& Rouse, 2016; ${ }^{3}$ Zmigrod et al., 2019; rest of references: Zmigrod et al., 2021; Zmigrod \& Poldrack, in prep.

Furthermore, dogmatism and lack of intellectual humility are associated with an impairment in the speed by which sensory evidence is accumulated from the perceptual environment (Zmigrod et al., 2021; Zmigrod \& Poldrack, in prep). Specifically, when participants were asked to complete perceptual decision-making tasks which required them to make a decision (e.g. whether dots on a screen are moving left or right), dogmatic participants were slower to accumulate and integrate the sensory evidence into a decision (e.g. deciding 
that the dots were moving to the left). In the language of computational cognitive science, dogmatic participants had a slower speed of evidence accumulation - called drift rate meaning they took longer to integrate sensory evidence in order to arrive at a decision than non-dogmatic participants (see Table 1, Figure 3). In contrast, nondogmatic, or intellectually humble, participants were consistently faster to accumulate sensory evidence across over a dozen cognitive tasks (Figures 3 and 5; Zmigrod et al., 2021; Zmigrod \& Poldrack, in prep), implying they were forming faster and more accurate decisions in these perceptual decisionmaking paradigms. This pattern of results suggests that dogmatic individuals are slower to process sensory evidence in perceptual decision-making tasks than their non-dogmatic peers.
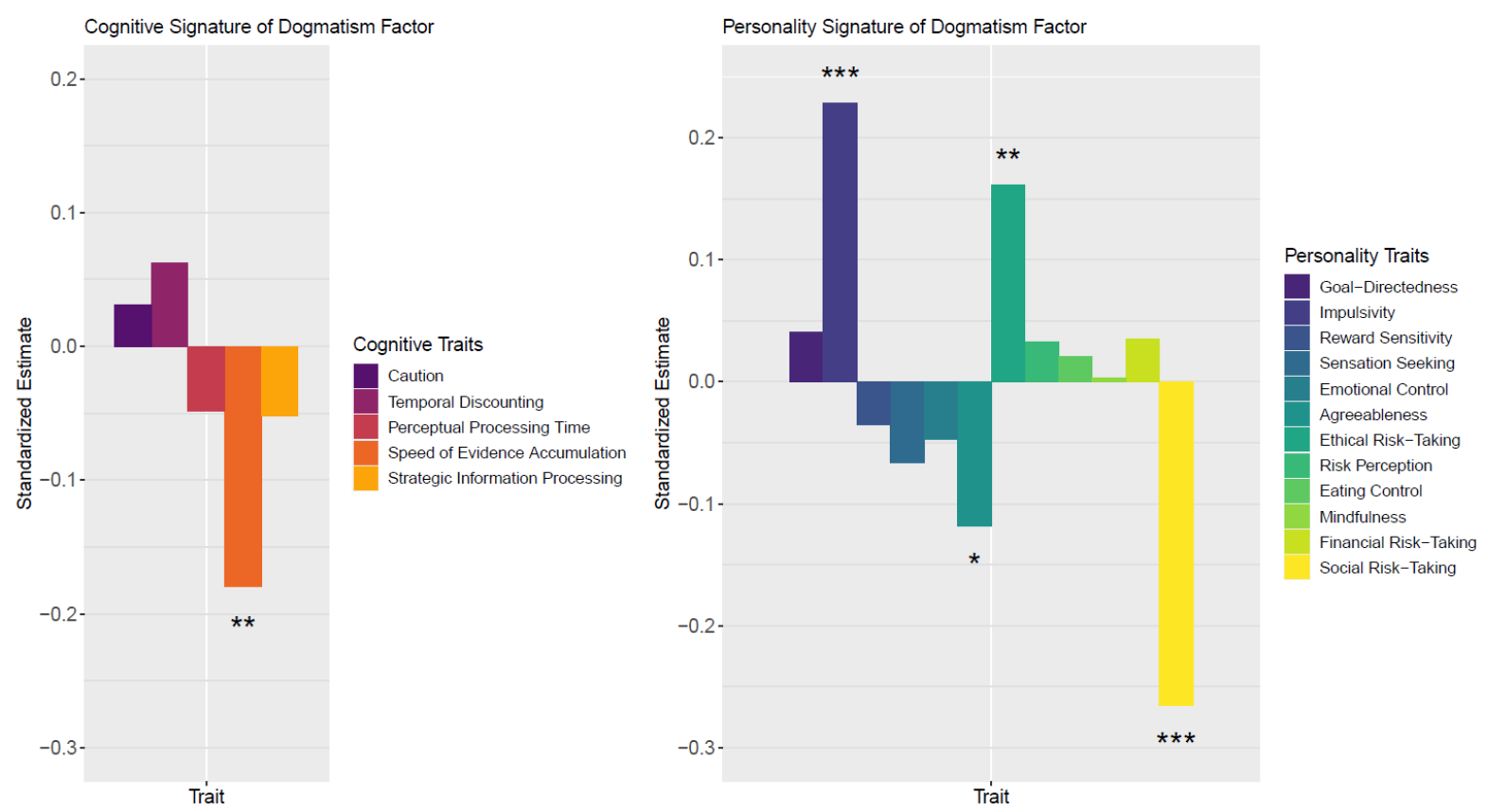

Figure 3. Individual-level cognitive and personality predictors of a summative dogmatism factor. Bars reflect standardized beta estimates of multiple linear regression analyses. Adapted with permission from Zmigrod et al (2021). *p<.05, **p<.01, ***p<.001.

Interestingly, dogmatic tendencies were also linked to an impulsive personality (Figures 3 and 4), while intellectual humility was associated with low impulsivity and high emotional control (Figure 5; Zmigrod et al., 2021). Consequently, dogmatism may be characterized by a disposition to make premature, impulsive decisions based on imperfectly 
processed evidence. Dogmatic individuals may thus have a unique cognitive and personality profile that renders them particularly susceptible to failures in processing perceptual evidence - which may percolate to failures in integrating ideological and politically-relevant evidence too. Further research into the precise processes by which domain-general aberrations in integrating evidence into decisions can lead to dogmatism will elucidate the causal mechanisms connecting perceptual dispositions and intolerant or overconfident beliefs.
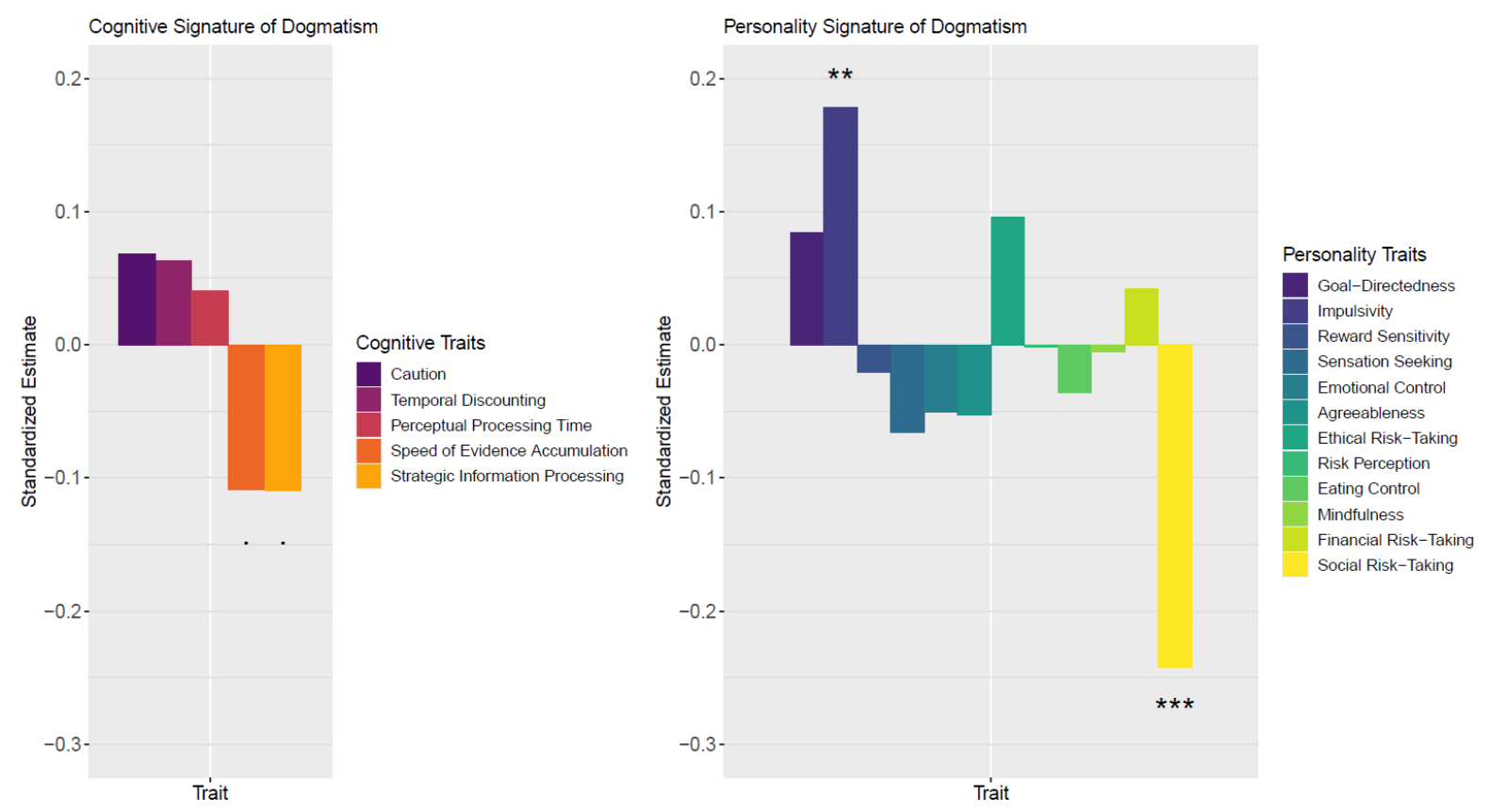

Figure 4. Individual-level cognitive and personality predictors of the dogmatism scale. Bars reflect standardized beta estimates of multiple linear regression analyses. Adapted with permission from Zmigrod et al (2021). *p<.05, **p<.01, ***p<.001.

The psychological profiles of the subdimensions of intellectual humility demonstrate common as well as unique cognitive and personality features for each dimension, revealing what makes a mind intellectually humble in general or in particular aspects (Table 1). All the dimensions of intellectual humility were implicated in a willingness to take social risks such as speaking in front of a crowd, disagreeing with an authority figure, or moving abroad (Figure 
5), indicating that intellectual humility is fundamentally tied to non- or anti-conformity. Moreover being intellectual humble was consistently related to a reduced willingness to take ethical risks such as cheating on an exam or having an affair (Figure 5). Intellectual humility therefore has a specific profile of risk-taking tendencies, favouring social non-conformity risks and avoiding ethical risks.

From a cognitive perspective, fast and effective sensory evidence accumulation was characteristic of individuals able to separate their intellect from their ego (Figure 5A), as well as those open to revising their beliefs (Figure 5B) and able to demonstrate respect for others' divergent viewpoints (Figure 5C). Furthermore, individuals who were open to belief updating (Figure 5B) exhibited low temporal discounting on behavioural tasks, indicating that they opted for delayed larger rewards over immediate smaller rewards. Receptivity to evidence and belief updating may thus be rooted in a capacity to delay gratification. This is corroborated by the personality findings, which show that low impulsivity was particularly characteristic of individuals willing to update their beliefs in light of evidence (Figure 5B) and those respectful of others' beliefs (Figure 5C). Intellectually humble individuals who do not feel threatened by intellectual disagreements also exhibited very high emotional control (Figure 5A), suggesting that intellectual humility of this kind requires affective self-regulation. These data-driven findings on the role of emotion control in intellectual humility can inform theories on the emotional roots of intellectual humility (Jarvinen \& Paulus, 2017; Krumrei-Mancuso, 2017; Leary et al., 2017; Porter \& Schumann, 2018).

Interestingly, some personality traits were positively predictive of one dimension of intellectual humility but negatively predictive of another, signifying patterns of specificity. For example, individuals scoring high on respect for others' viewpoints tended to be psychologically highly sensitive to rewards (Figure 5C), whereas individuals who tend to be intellectually overconfident are also sensitive to rewards (Figure 5D). Could both respect for 
others' viewpoints and intellectual overconfidence confer rewards? This question is pertinent for motivated reasoning accounts that often implicitly assume respect for and acceptance of alternative or incongruent viewpoints would be cognitively costly, rather than rewarding. These nuanced patterns of results suggest that a further examination of the relationship between reward sensitivity and intellectual humility could be a valuable contribution to the literature delineating psychological mechanisms facilitating intellectual humility.

Figure 5. Individual-level cognitive and personality predictors of the intellectual humility scales. Scales include: (A) Independence of intellect and ego, (B) Openness to belief updating, (C) Respect for others' beliefs, (D) Lack of intellectual overconfidence. Bars reflect standardized beta estimates of multiple linear regression analyses. Adapted with permission from Zmigrod et al (2021). *p<.05, **p<.01, ***p<.001.

A
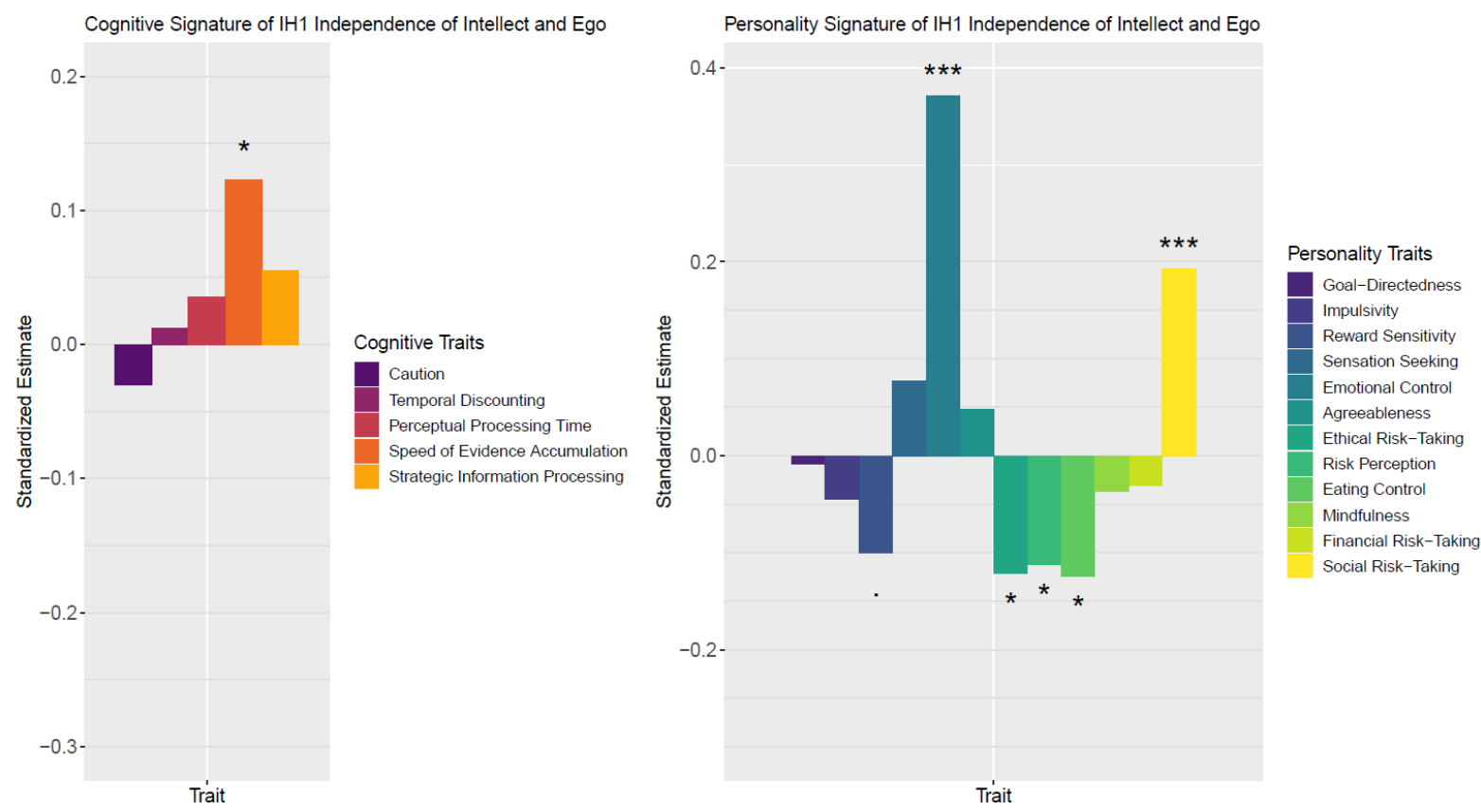

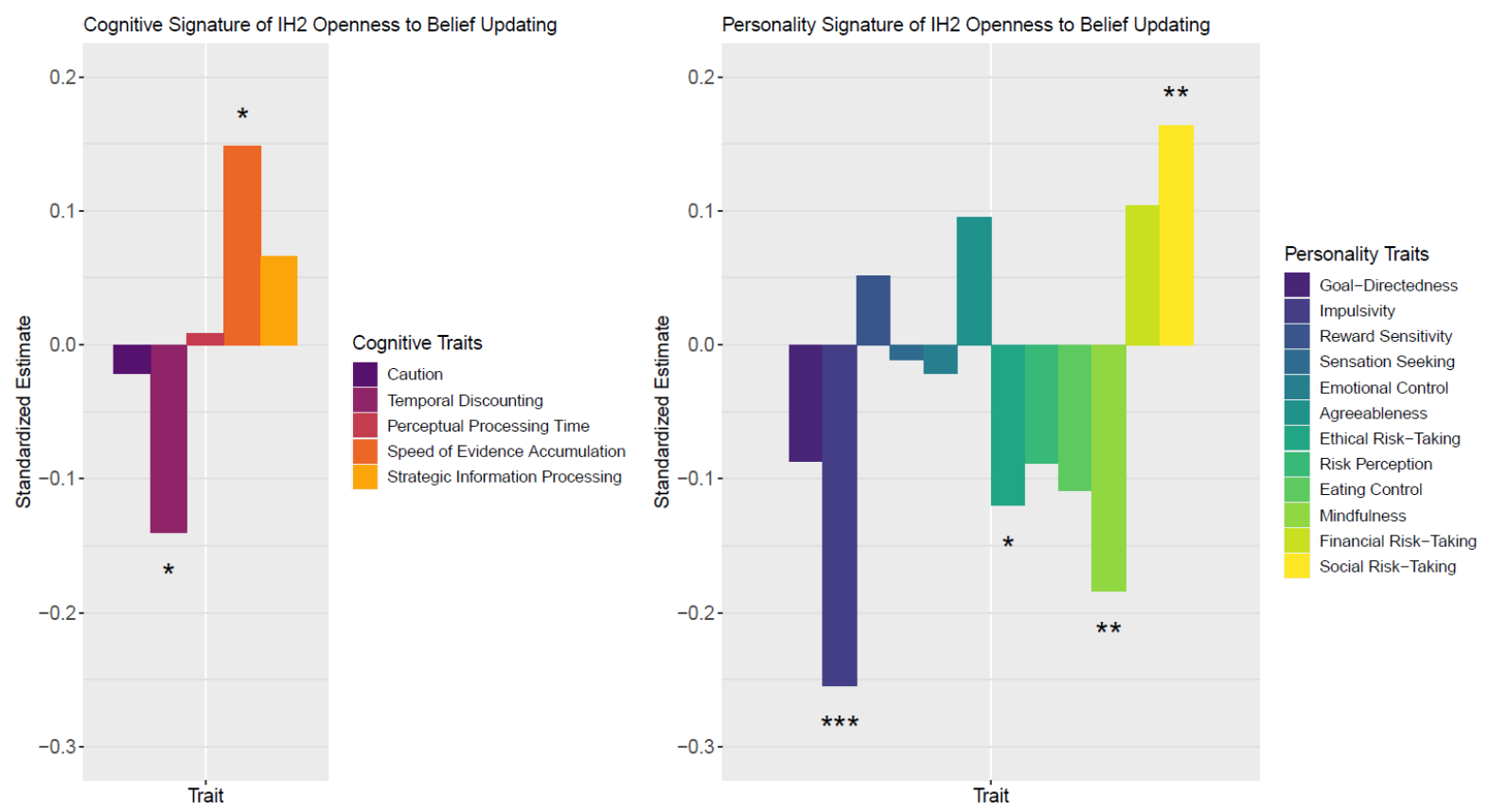

C
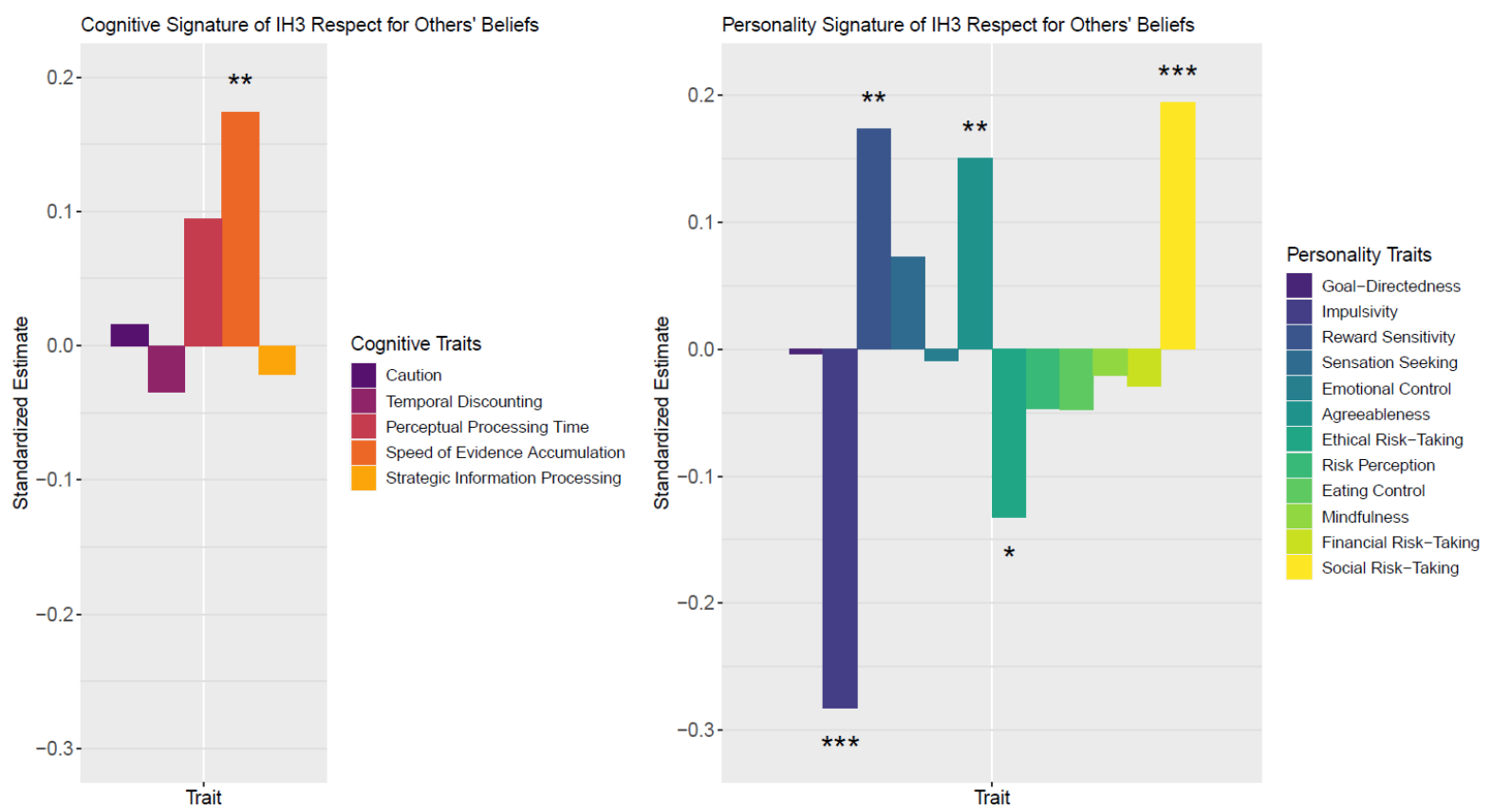
D
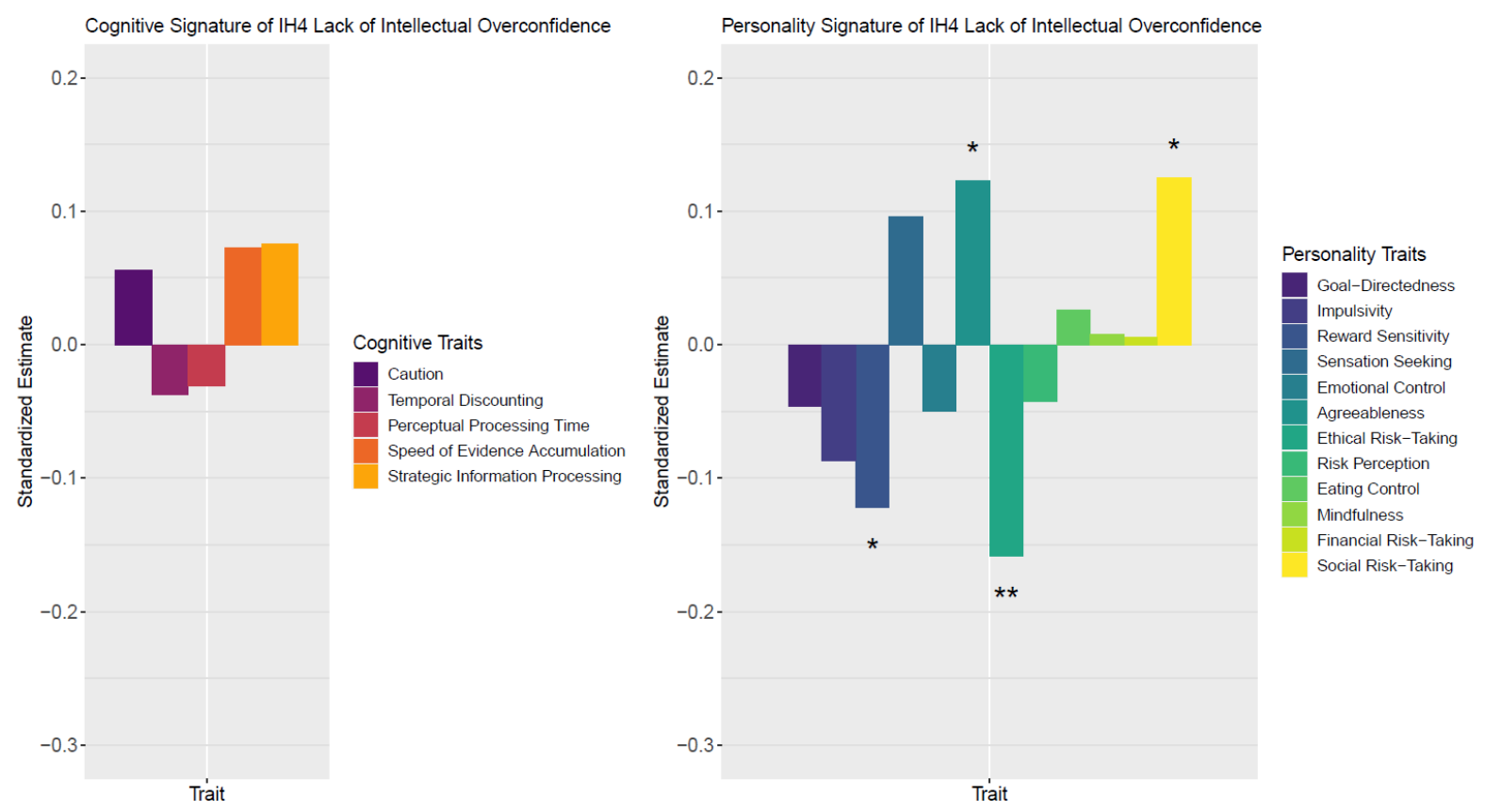

Political Ideologies:

Political psychologists have identified several ideological orientations that reliably capture citizens' stable attitudes regarding social arrangements, intergroup relations, and policy preferences. Eight primary ideological worldviews recur throughout political psychology and so their cognitive and personality correlates merit particular attention. These ideologies include social conservatism, economic conservatism, nationalism, patriotism, authoritarianism, social dominance orientation, system justification, and extreme pro-group attitudes. Factor analysis of these ideologies revealed that they tap into a unitary dimension that can broadly be labelled as political conservatism (Zmigrod et al., 2021). Examining the psychological signature of the summative political conservatism factor (Figure 6) as well as the separable ideological orientations (Table 2; Figures 7-11) enables an accessible comparison of the commonalities and differences between these political ideologies.

In the domain of behaviourally-assessed perceptual and cognitive traits, politically conservative ideologies are consistently characterized by so-called perceptual caution (Figure 
6, Table 2). In perceptual decision-making paradigms, participants are asked to make rapid decisions based on perceptual stimuli, such as deciding whether dots are moving to the left or the right of the screen (e.g. in a dot pattern expectancy task) or deciding when they must inhibit a prepotent response (e.g. in a stop-signal task). Participants are instructed to act as quickly and as accurate as possible, and so there is inevitably a speed-accuracy trade-off whereby individuals implicitly opt for cautious slow-and-steady perceptual strategies (prioritizing accuracy over speed) or for more hasty fast-and-furious strategies (which prioritize speed over accuracy). Computational modelling with drift-diffusion models can be applied to the trial-bytrial behaviour on these tasks so that an individual difference parameter is extracted that captures each individual's level of perceptual caution, or implicit trade-off between speed and accuracy. Notably, individuals with more politically conservative (i.e. cautious) worldviews adopted more cautious perceptual strategies on these neutral perceptual decision-making tasks (Figure 6; Table 2; Zmigrod et al., 2021). This parallel between low-level psychophysical caution and high-level ideological caution is striking. The results are congruent with the Neurocognitive Model of Ideological Thinking's assertion that individual differences in neurocognition shape proclivities for ideological thinking. The findings further highlight that purely motivational accounts that disregard neurocognition may be missing notable characteristics in the brains of ideologues.

In addition, political conservatives performed poorly on higher-order executive function tasks that require planning, flexibility, and mental simulations, i.e. strategic information processing (Figure 6; Table 2). A cognitive difficulty with complexity may predispose individuals to adhere to ideological doctrines that reduce complexity. This datadriven finding is consistent with a vast literature positing relationships between cognitive ability and right-wing attitudes (e.g. Heaven, Ciarrochi, \& Leeson, 2011; Hodson \& Busseri, 
2012; Onraet et al., 2015), and suggests that these impairments in strategic information processing are evident across a wide variety of behavioural tasks (Zmigrod et al., 2021).
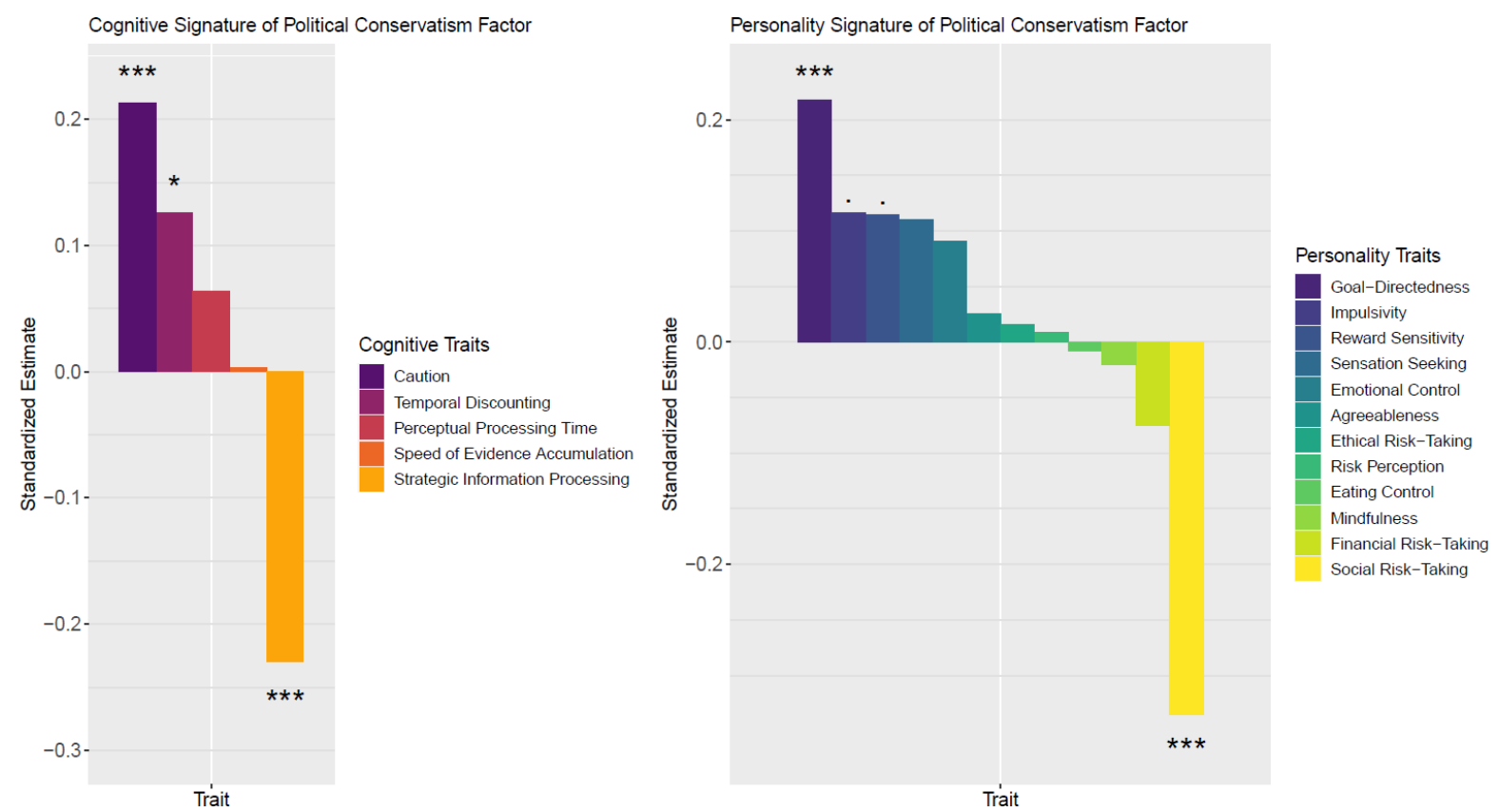

Figure 6. Individual-level cognitive and personality predictors of the summative political conservatism factor. Bars reflect standardized beta estimates of multiple linear regression analyses. Adapted with permission from Zmigrod et al (2021). *p<.05, **p<.01, ***p<.001.

Finally, political conservatism was marked by a greater cognitive tendency for temporal discounting (Figure 6; Table 2), implying that conservative individuals were more likely to prefer smaller immediate rewards over larger delayed rewards when given the two options in intertemporal decision-making tasks (Zmigrod et al., 2021). Temporal discounting has been studied in the context of sacred values (Sheikh, Ginges, \& Atran, 2013), religion (Paglieri, Borghi, Colzato, Hommel, \& Scorolli, 2013), and beliefs (Shenhav, Rand, \& Greene, 2017), where it has been demonstrated that steeper discounters prefer consuming more simplistic and unidimensional information and possess interpersonal and religious beliefs marked by reduced epistemic complexity (Shenhav, Rand, \& Greene, 2017). 
The finding that conservative individuals are steeper temporal discounters and more impulsive may initially seem to be at odds with the finding that perceptually, nationalistic participants were more cautious (Zmigrod et al., 2021). There are two key elements to understanding these patterns: (a) an immediate reward is experienced as more certain than a delayed reward (Halevy, 2008; Keren \& Roelofsma, 1995), and so the conservative strategy to guarantee certainty would be to experience the reward as soon as possible, and (b) temporal discounting involves decisions that take place on wider time scales than the caution measured in perceptual decision-making. Hence, politically conservative individuals may have cautious perceptual strategies that shape how they experience sensory evidence and low-level belief formation, yet be more impulsive and impatient when it comes to higher-order decisions and information at slower or longer timeframes.

In terms of personality traits, politically conservative ideologies were united in being characterized by high goal-directedness, indexed by a self-reported ability to persevere with goals and resist temptations, and low social risk-taking, which involves instances of nonconformity and non-obedience, such as disagreeing with an authority figure on a key issue (Figure 6; Zmigrod et al., 2021). However, each political ideology also had its own unique personality signature that differentiated it from others (Table 2) and so it is fruitful to examine each ideological worldview independently in order to identify their psychological similarities and dissimilarities.

Table 2. Summary of results on cognitive and personality correlates of political conservatism and associated constructs.

\begin{tabular}{llll}
\hline & Example Items & Cognitive Traits & Personality Traits \\
\hline Social & "I feel negatively & Cognitive rigidity & High goal-directedness \\
Conservatism $^{1}$ & about abortion" & High caution & High agreeableness \\
& & High perceptual & High risk perception \\
& & processing time & Low social risk-taking \\
& & Low strategic \\
& & \\
& &
\end{tabular}




\begin{tabular}{|c|c|c|c|}
\hline $\begin{array}{l}\text { Economic } \\
\text { Conservatism }^{1}\end{array}$ & $\begin{array}{l}\text { "I feel negatively } \\
\text { about welfare } \\
\text { benefits" }\end{array}$ & High caution & $\begin{array}{l}\text { High goal-directedness } \\
\text { High sensation-seeking } \\
\text { Low social risk-taking }\end{array}$ \\
\hline Nationalism ${ }^{2}$ & $\begin{array}{l}\text { "We should do } \\
\text { anything necessary } \\
\text { to increase the } \\
\text { power of our } \\
\text { country, even if it } \\
\text { means war" }\end{array}$ & $\begin{array}{l}\text { Cognitive rigidity } \\
\text { High caution } \\
\text { High temporal } \\
\text { discounting } \\
\text { Low strategic } \\
\text { information processing }\end{array}$ & $\begin{array}{l}\text { High goal-directedness } \\
\text { High reward sensitivity } \\
\text { High impulsivity } \\
\text { Low social risk-taking }\end{array}$ \\
\hline Patriotism $^{3}$ & $\begin{array}{l}\text { "I have great love } \\
\text { for my country" }\end{array}$ & $\begin{array}{l}\text { High caution } \\
\text { High perceptual } \\
\text { processing time } \\
\text { Low strategic } \\
\text { information processing }\end{array}$ & $\begin{array}{l}\text { High goal-directedness } \\
\text { High reward sensitivity } \\
\text { High agreeableness } \\
\text { High risk perception } \\
\text { Low social risk-taking }\end{array}$ \\
\hline Authoritarianism ${ }^{4}$ & $\begin{array}{l}\text { "Children should } \\
\text { be obedient rather } \\
\text { than independent" }\end{array}$ & $\begin{array}{l}\text { Cognitive rigidity } \\
\text { High temporal } \\
\text { discounting } \\
\text { Fast sensory evidence } \\
\text { accumulation } \\
\text { Low strategic } \\
\text { information processing }\end{array}$ & $\begin{array}{l}\text { High goal-directedness } \\
\text { Low social risk-taking }\end{array}$ \\
\hline $\begin{array}{l}\text { Social Dominance } \\
\text { Orientation }^{5}\end{array}$ & $\begin{array}{l}\text { "Superior groups } \\
\text { should dominate } \\
\text { inferior groups" }\end{array}$ & $\begin{array}{l}\text { High caution } \\
\text { Slow sensory evidence } \\
\text { accumulation }\end{array}$ & $\begin{array}{l}\text { High goal-directedness } \\
\text { High impulsivity } \\
\text { Low agreeableness } \\
\text { High ethical risk-taking } \\
\text { Low mindfulness } \\
\text { Low social risk-taking }\end{array}$ \\
\hline $\begin{array}{l}\text { System } \\
\text { Justification }^{6}\end{array}$ & $\begin{array}{l}\text { "American society } \\
\text { is set up so that } \\
\text { people usually get } \\
\text { what they deserve" }\end{array}$ & High caution & $\begin{array}{l}\text { High goal-directedness } \\
\text { High impulsivity } \\
\text { High emotional control } \\
\text { Low social risk-taking }\end{array}$ \\
\hline $\begin{array}{l}\text { Extreme Pro- } \\
\text { group Attitudes }\end{array}$ & $\begin{array}{l}\text { "I would help } \\
\text { others get revenge } \\
\text { on someone who } \\
\text { insulted my } \\
\text { country" }\end{array}$ & $\begin{array}{l}\text { Cognitive rigidity } \\
\text { High caution } \\
\text { Low strategic } \\
\text { information processing } \\
\text { Slow perceptual } \\
\text { processing }\end{array}$ & $\begin{array}{l}\text { High goal-directedness } \\
\text { High impulsivity } \\
\text { High sensation-seeking } \\
\text { Low social risk-taking }\end{array}$ \\
\hline $\begin{array}{l}\text { Political } \\
\text { Conservatism } \\
\text { Factor }\end{array}$ & $\begin{array}{l}\text { Scores from factor } \\
\text { analysis including } \\
\text { eight sub-scales } \\
\text { above }\end{array}$ & $\begin{array}{l}\text { High caution } \\
\text { High temporal } \\
\text { discounting } \\
\text { Low strategic } \\
\text { information processing }\end{array}$ & $\begin{array}{l}\text { High goal-directedness } \\
\text { Low social risk-taking }\end{array}$ \\
\hline \multicolumn{4}{|c|}{$\begin{array}{l}{ }^{1} \text { Everett, 2013; }{ }^{2} \text { Sidanius, Feshbach, Levin, \& Pratto, 1997; }{ }^{3} \text { Federico, Golec, \& Dial, 2005; } \\
{ }^{4} \text { Hetherington \& Weiler, 2009; }{ }^{5} \text { Pratto et al., 2013; }{ }^{6} \text { Kay \& Jost, 2003; }{ }^{7} \text { Swann et al., 2009; }{ }^{8} \text { Zmigrod, } \\
\text { Rentfrow, \& Robbins, 2018; }{ }^{9} \text { Zmigrod, Rentfrow, \& Robbins, 2019, 2020; rest of references: Zmigrod } \\
\text { et al., 2021. }\end{array}$} \\
\hline
\end{tabular}




\section{Social and Economic Conservatism:}

Social psychology has long acknowledged that political conservatism can be decomposed into social (or cultural) conservatism and economic conservatism (Everett, 2013; Johnson \& Tamney, 2001). The social or cultural dimension concerns attitudes on issues such as traditional values, immigration, sexual rights and morality, while the economic dimension reflects preferences with regards to redistributive welfare benefits and taxation (Carmines \& D'Amico, 2015). Investigations into the ideological and personality correlates of social and economic conservatism show that social-cultural conservatism is typically characterized by greater dogmatism and dogmatic aggression as well as a need for structure and for cognition (e.g. Crowson, 2009). Nevertheless, there has not been a systematic data-driven examination of the psychological predictors of social and economic conservatism using cognitive tasks and personality surveys (selected agnostically, not in relation to political psychology research; Eisenberg et al., 2018, 2019). Are social and economic conservatives similar in their perception, cognition, and personality?

Both social and economic conservatives exhibited perceptual caution in neuropsychological tasks (Figure 7), whereby trial-by-trial analyses of fast perceptual decisions, conservative individuals tended to prefer slow-and-accurate strategies. This contrasts to liberals' tendencies for faster-and-erroneous perceptual strategies, and suggests that caution at the level of low-level perception mirrors conservative caution at high-level ideological attitudes (Zmigrod, 2021; Zmigrod et al., 2021). Over the last decade, there has been a raging debate in political psychology regarding whether political conservatism is likely to be endorsed by threat-sensitive individuals (Hibbing, Smith, \& Alford, 2014), whose sensitivity to threat might even be visible in psychophysiological recordings (Smith \& Warren, 2020). Whereas some research groups observe relationships between physiological predispositions and political inclinations (Dodd et al., 2012; Knoll, O’Daniel, \& Cusato, 2015; 
Oxley et al., 2008; Smith et al., 2011), recent critical replications have failed to conclude that electrodermal activity is a reliable index of threat sensitivity (Bakker et al., 2020; Osmundsen et al., 2021). Could it be that instead of threat sensitivity, the underlying difference between political conservatives and liberals rests in sensory caution instead? Investigating this hypothesis could help resolve the inconsistent empirical findings in political psychophysiology.

Further points of similarity between the profiles of social and economic conservatism include significantly diminished strategic information processing, indexed by executive function tasks tapping into planning, working memory, and flexibility (Figure 7). This finding corroborates past theory-driven research on cognitive ability and cognitive style (Jost, 2017; Onraet et al., 2015; Van Hiel et al., 2016; Zmigrod, 2020) and suggests that liberals outperform conservatives on a range of executive function tasks. From a personality perspective, social and economic conservatives were both characterized by high goal-directedness and low social risk-taking, in line with most of the other right-leaning political ideologies tested (Table 2).

Points of difference were evident in the finding that social, but not economic, conservatives were slower to process non-decision-related sensory evidence than their liberal peers, indicating they experienced a sensory delay and were slower to initiate motor responses in perceptual decision-making tasks (Figure 7). Could a basic sensory impairment promote a preference for more traditional worldviews which allow for greater predictability and stability? Empirical corroboration and theoretical elaboration are essential for comprehending the significance of these findings. Intriguingly, economic conservatives were more sensationseeking than economic liberals (Figure 7). Perhaps this calls for a problematization of our views of economic conservatives as necessarily akin to right-wing ideologues (Johnson \& Tamney, 2001); indeed cross-cultural analyses show that personality preferences for conformity, security, and tradition frequently predict left-wing economic attitudes (Malka, Soto, Inzlicht, 
\& Lelkes, 2014). In addition, social conservatives also tended to be more agreeable and had heightened risk perception than social liberals (Figure 7), illustrating that social conservatism may entail greater sensitivity to the riskiness of potentially risky behaviours. Echoing Allport's (1954) quote in the epigraph, prejudices and ideological attitudes are likely to be reflections of domain-general psychological habits and tendencies, and so a general perceptiveness of risks is an apt predictor of traditionally-minded social conservatism.
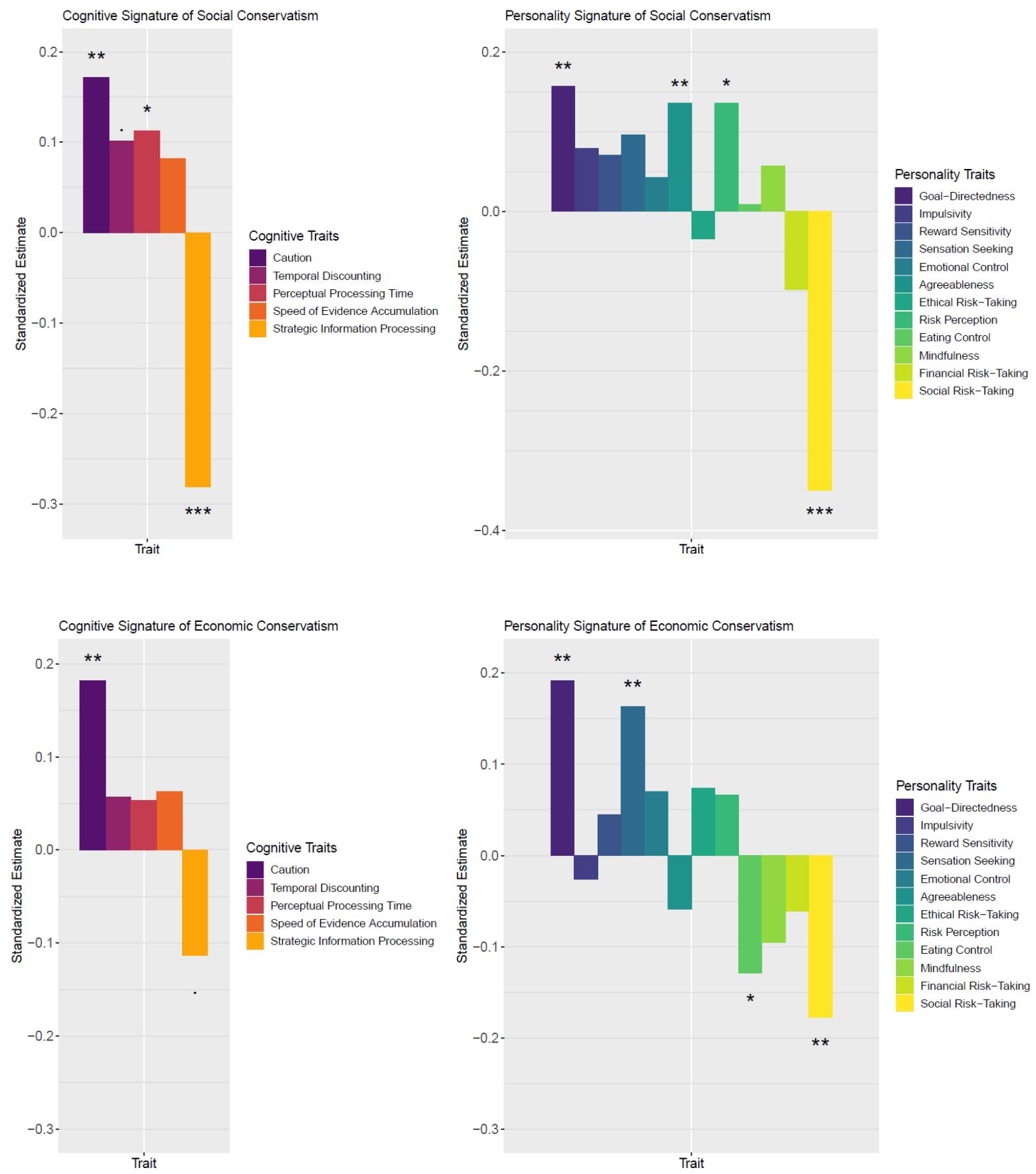
Figure 7. Individual-level cognitive and personality predictors of $(A)$ social conservatism and (B) economic conservatism. Bars reflect standardized beta estimates of multiple linear regression analyses. Adapted with permission from Zmigrod et al (2021). ${ }^{o} p<.06$, *p<.05, $* * p<.01, * * * p<.001$.

\section{Nationalism and Patriotism:}

Although often linked, nationalism and patriotism tap into separable ideological tendencies: nationalism reflects a belief in national superiority and dominance while patriotism is focused on a love and prideful admiration for one's nation and national culture (Feshbach \& Sakano, 1997; Huddy \& Khatib, 2007; Kosterman \& Feshbach, 1989; Sidanius, Feshbach, Levin, \& Pratto, 1997). In terms of their cognitive and personality signatures, both nationalism and patriotism were characterized by a perceptual strategy towards caution, whereby nationalistic and patriotic individuals tended to prioritize accuracy over speed in timed perceptual decision-making tasks involving arbitrary visual stimuli (Figure 8; Zmigrod et al., 2021). Caution is implicated in the signatures of all other studied conservative ideologies, with the exception of authoritarianism (see Table 2), suggesting perceptual caution may reflect a core correlate of politically cautious and traditional ideologies favouring the status quo. Furthermore, nationalistic and patriotic individuals exhibited poor performance on strategic information processing tasks require complex mental computations and planning (Figure 8) suggesting that a cognitive difficulty with high-order executive functions and complexity may lend itself to the adoption of simplifying nationalistic ideologies and beliefs.

The personality signatures of nationalism and patriotism revealed that both were characterized by heightened goal-directedness and reward sensitivity (Figure 8). These findings raise provocative theoretical questions: what kinds of goals do nationalistic ideologies 
satisfy that make them appealing to goal-directed individuals? And what kinds of rewards might nationalistic ideologies offer that make them more attractive for reward-sensitive individuals? Few, if any, psychological theories of ideologies explicitly incorporate psychological notions of goals and rewards, unless these are subsumed by "motivational" theories of political behaviour that discuss identity-protective and motivated reasoning (e.g. Jost et al., 2003; Van Bavel \& Pereira, 2018). Nevertheless, there is evidence that when participants are offered (vs. not offered) monetary incentives to complete behavioural tasks, individuals high in right-wing authoritarianism perform better, while individuals low in rightwing authoritarianism are unaffected by the monetary rewards (Burger, Pfattheicher, \& Jauch, 2020). Exploring whether and why goal-directed and reward-sensitive individuals gravitate towards nationalistic ideologies may be a fruitful avenue for research.

There are several notable areas of discrepancies between the psychological profiles of nationalism and patriotism. Like political conservatives, but unlike patriots, nationalistic individuals were steep temporal discounters, signifying they preferred smaller immediate rewards over larger delayed rewards when asked whether they would delay gratification to receive a larger reward later in intertemporal decision-making tasks (Zmigrod et al., 2021). Patriotic individuals tended to score more highly on agreeableness than their non-patriotic peers and were also more highly perceptive of risks (Figure 8). Interestingly, there is a burgeoning literature on the relationship between risk perceptions and attachment to nations and local regions in the study of environmental behaviour; as citizens face ecological or conflict-based risks in their local environments, a question arises regarding whether heightened risk perception would lower or amplify one's attachment to the place, and vice versa (Bernardo, 2013; Billig, 2006; Yu, Chang, Chang, \& Yu, 2019). In the context of patriotism, research on the aftermath of $9 / 11$ suggests that the experience of threat, anxiety, and insecurity translated into national security policy preferences that alleviated these emotions (Huddy \& Feldman, 
2011). It is plausible that a general sensitivity to perceiving risks would be linked to greater patriotic attachment - but this requires further theoretical elaboration and empirical support.
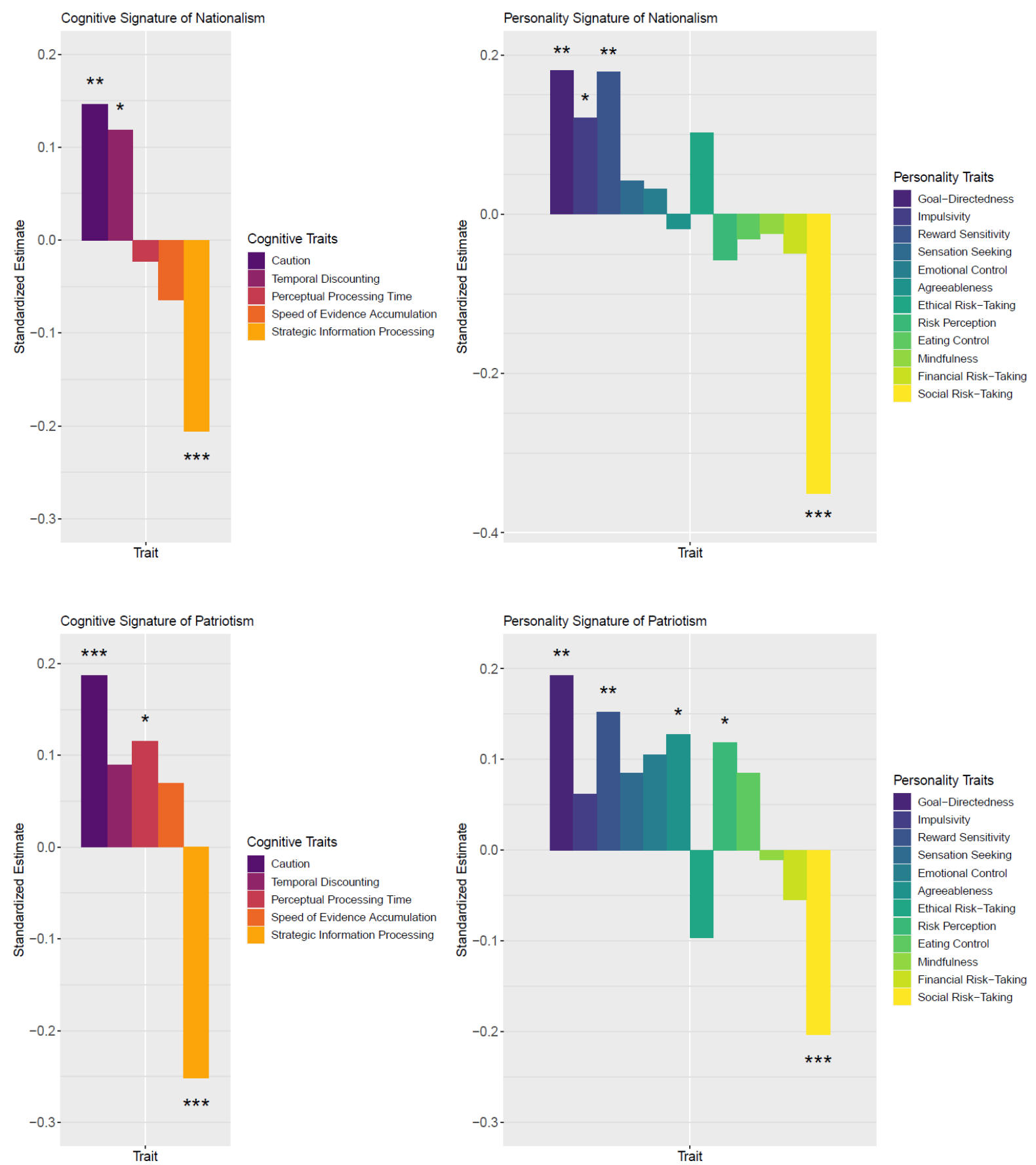

Figure 8. Individual-level cognitive and personality predictors of $(A)$ nationalism and $(B)$ patriotism. Bars reflect standardized beta estimates of multiple linear regression analyses. Adapted with permission from Zmigrod et al (2021). *p<.05, **p<.01, ***p<.001. 
Authoritarianism, Social Dominance Orientation, and System Justification:

Prominent psychological theories on the structure of ideological attitudes centre on three ideological constructs: authoritarianism, social dominance orientation (SDO), and system justification (SJ). Duckitt and Sibley’s (2010) influential dual-process motivational model hypothesizes that social dominance orientation and (right-wing) authoritarianism are two dimensions of social attitudes which reflect differing motivational values of establishing and maintaining collective security (right-wing authoritarianism) and competitiveness over group dominance (social dominance orientation). SDO and right-wing authoritarianism have been shown to be complementary and unique predictors of prejudice (Altemeyer, 1998; Cichocka, Dhont, \& Makwana, 2017; Hodson \& Dhont, 2015; Son Hing \& Zanna, 2010; Van Hiel \& Mervielde, 2005) and have been useful for understanding ideological phenomena including antiscientific attitudes (Azevedo \& Jost, 2021), economic protectionism (Jedinger \& Burger, 2020), social status (Vargas-Salfate et al., 2018), and environmentalism (Stanley, Wilson, \& Milfont, 2017; Stanley, Milfont, Wilson, \& Sibley, 2019). Similarly, system justification theory has revealed that preferences to maintain the status quo shapes individuals' agreement with prejudiced stereotypes (Calogero \& Jost, 2011; Kay \& Jost, 2003) and reduces the probability that they engage in collective action to reduce societal inequality (Jost, Becker, Osborne, \& Badaan, 2017; Wakslak, Jost, Tyler, \& Chen, 2007). While there have been several studies on the relationships between the Big Five personality inventory and authoritarianism, SDO, and SJ, there have been few efforts to map out the cognitive antecedents of these ideological dimensions, or to examine a broader range of implicated personality traits beyond the Big Five.

The psychological profile of authoritarianism possesses some of the features evident in conservatism and nationalism, including poor strategic information processing on high-level executive function tasks and a tendency towards temporal discounting, signalling a difficulty to delay rewarding gratifications (Table 2; Figure 9). Hodson and Busseri (2012) found that 
right-wing authoritarians (note that the authoritarianism scale used in Zmigrod et al., 2021 was not explicitly right-wing) performed poorly on measures of abstract reasoning, corroborating the effect of strategic information processing here. Authoritarian individuals also exhibit the heightened goal-directedness and diminished social risk-taking implicated in most politically conservative ideologues (Figure 9). One result that remains difficult to explain theoretically is that authoritarians had a high speed of sensory evidence accumulation on perceptual decisionmaking tasks, suggesting that they are particularly adept at integrating sensory evidence into cognitive decisions. This pattern diverges from the profiles of dogmatism (Figure 3) and social dominance orientation (Figure 10), whereby dogmatic and high SDO individuals tend to have diminished evidence accumulation rates and so exhibit an impairment in this cognitive domain. Further explication of this pattern of results for authoritarian individuals will help shed light on how to interpret this finding.
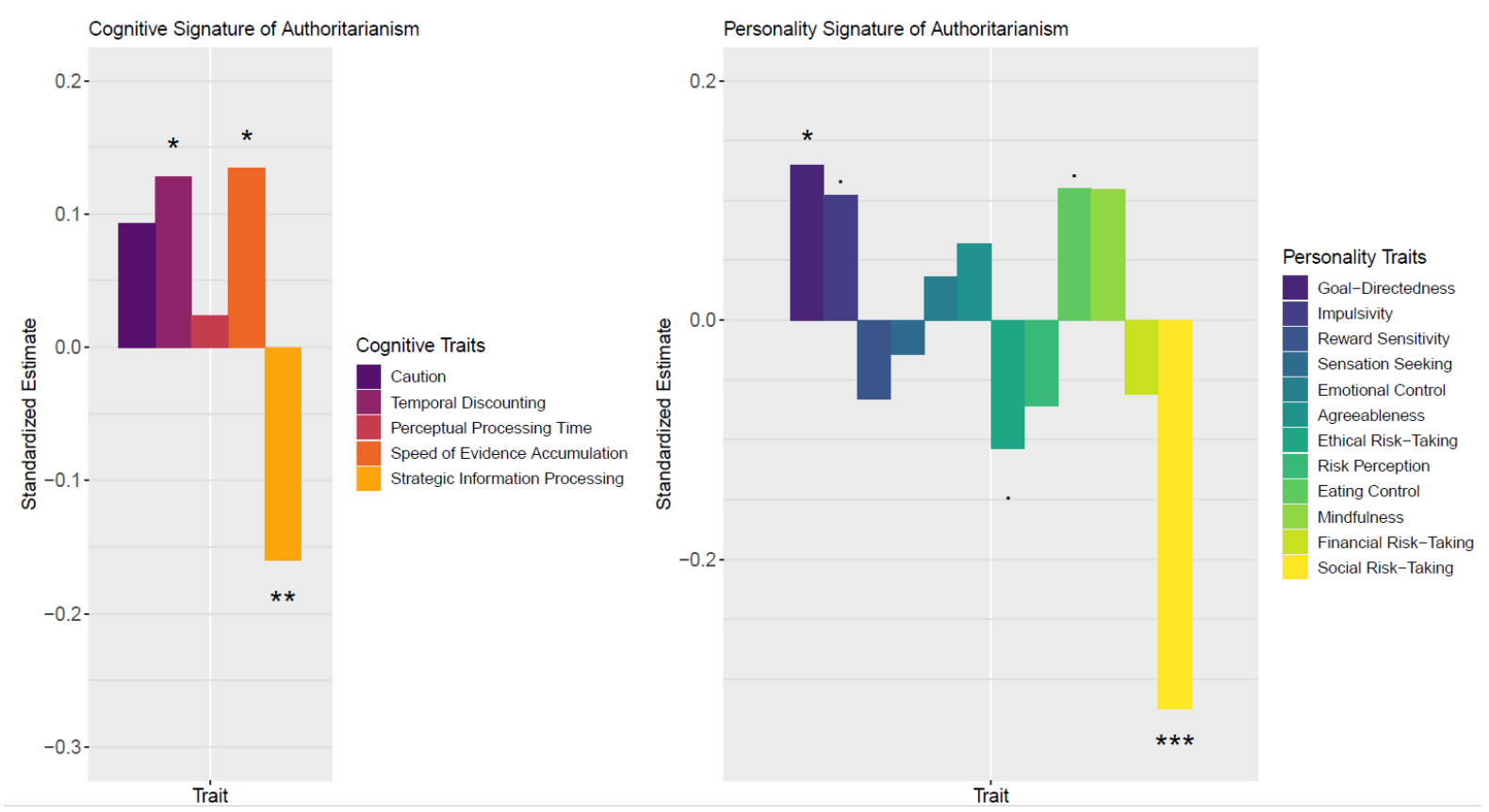

Figure 9. Individual-level cognitive and personality predictors of authoritarianism. Bars reflect standardized beta estimates of multiple linear regression analyses. Adapted with permission from Zmigrod et al (2021). *p<.05, **p<.01, ***p<.001. 
The cognitive and personality signature of SDO resembles a mix of features from the politically conservative ideologies as well as the dogmatism and (inverse of the) intellectual humility scales. Like the profiles of other politically conservative ideologies (Figures 6), individuals with high SDO were more perceptually cautious than their low SDO peers, and possessed the personality traits of goal-directedness, impulsivity, and low social risk-taking (Figures 10). Furthermore, in a mirror image to the intellectual humility scales (Figures 3 and 5), SDO individuals had slower and impaired evidence accumulation processing in perceptual decision-making tasks, and exhibited high ethical risk-taking tendencies and low agreeableness (in concordance with other studies linking SDO with low agreeableness; Duckitt \& Sibley, 2010; Sibley \& Duckitt, 2008). Individuals high in SDO were also characterized by low mindfulness. These patterns are consistent with motivational theories on the origins of SDO which posit SDO emerges from a worldview belief that the world resembles a ruthless competitive jungle (Duckitt \& Sibley, 2010) and so perceptual caution along with a Machiavellian-like tendency for goal-directedness, ethical risk-taking, and impulsivity, as well as low agreeableness and mindfulness, reflect a theoretically plausible psychological profile that could mimic adaptations for such a worldview.
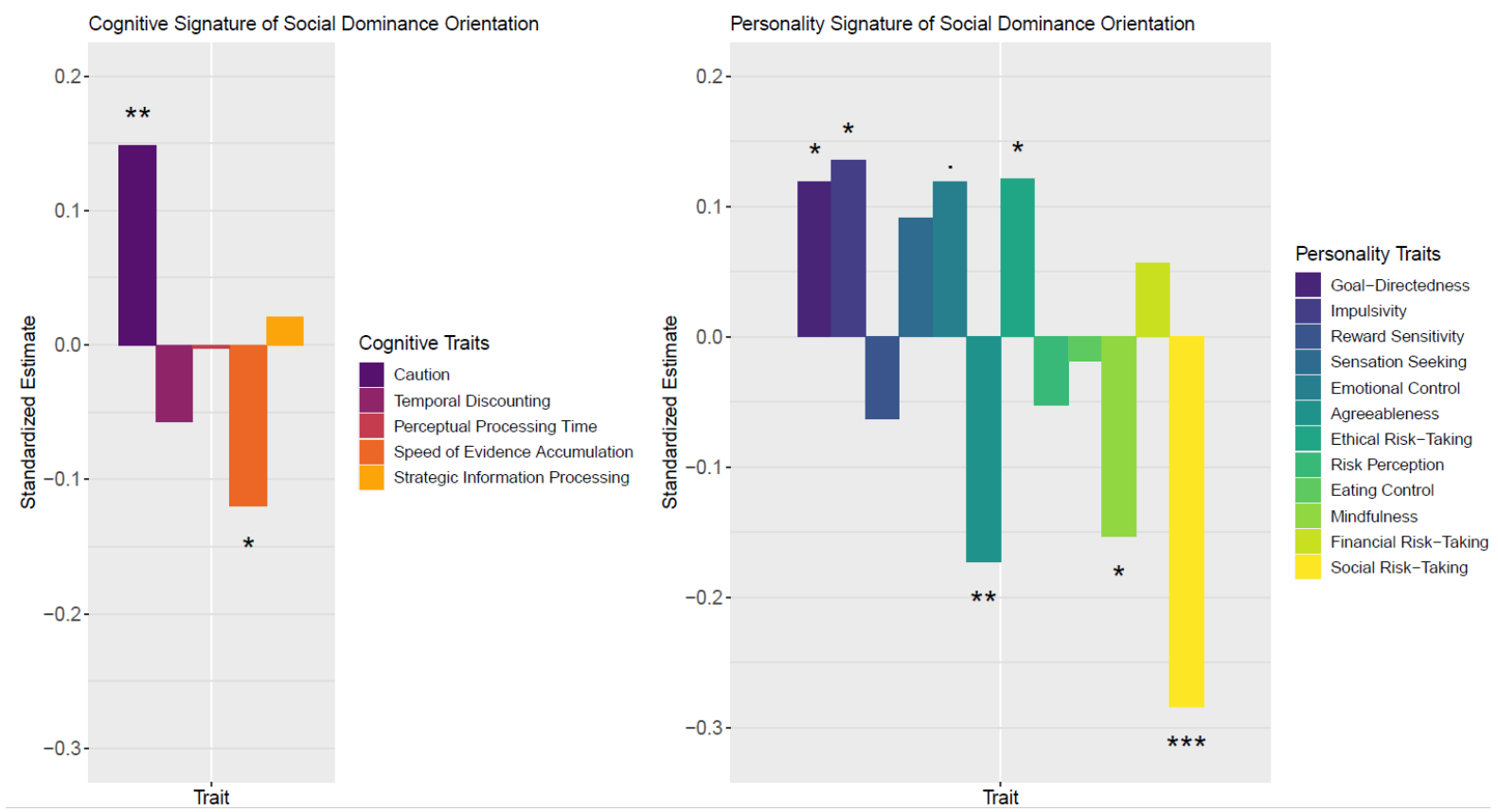

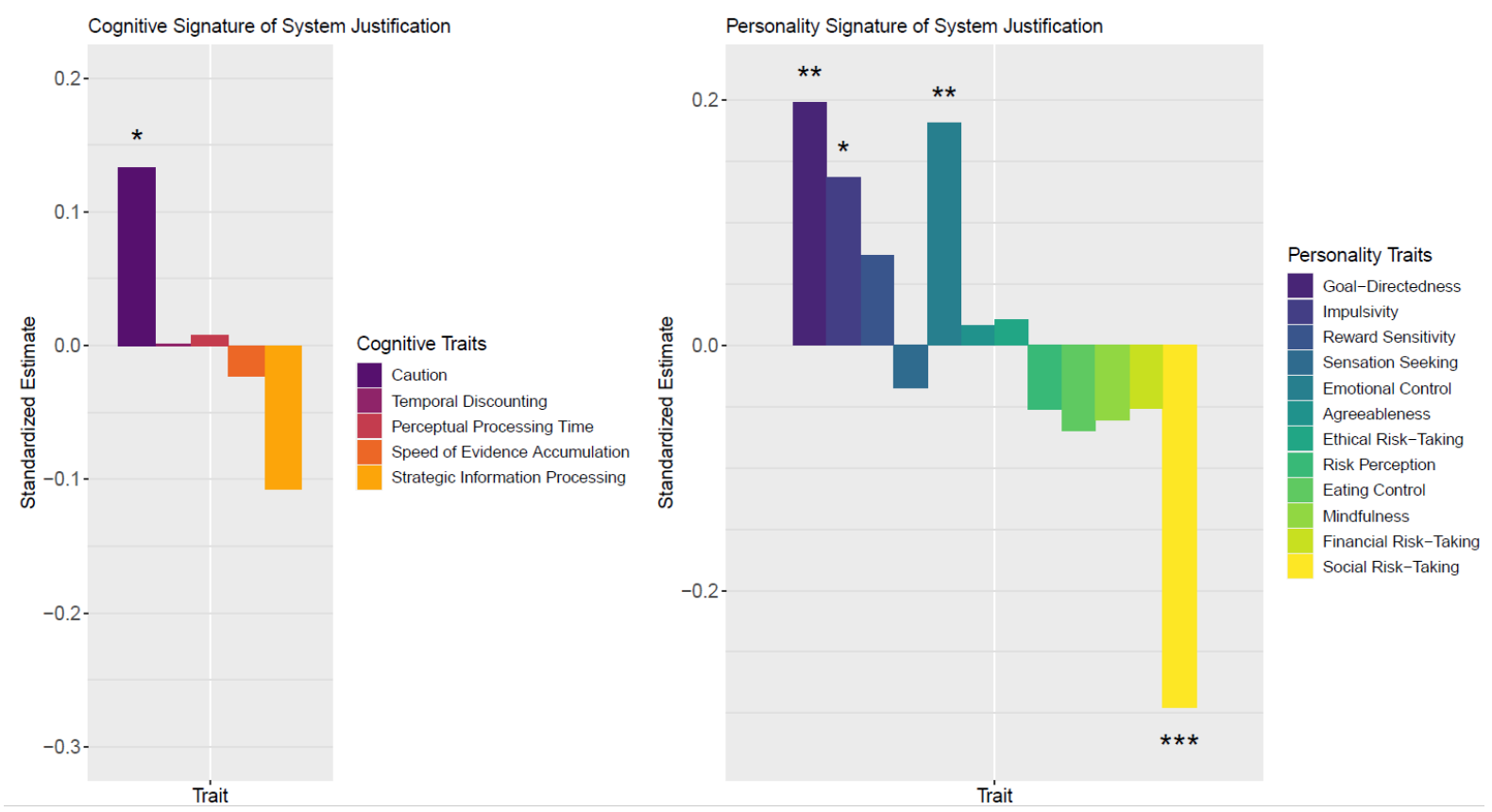

Figure 10. Individual-level cognitive and personality predictors of (A) social dominance orientation and (B) system justification. Bars reflect standardized beta estimates of multiple linear regression analyses. Adapted with permission from Zmigrod et al (2021). *p<.05, $* * p<.01, * * * p<.001$.

The psychological characteristics of individuals who were high in system justification, indicating they regarded existing (unequal) social systems to be legitimate and desirable, resembled the characteristics of individuals with strong preferences for social hierarchies (SDO). High system justifiers were more perceptually cautious in the cognitive domain than low system justifiers, and exhibited high goal-directedness, emotional control, and low social risk-taking (Figure 10). In line with other conservative political ideologies, high system justifiers struggled to inhibit impulsive responses (Table 2).

Notably, SDO and SJ were the only political ideologies not to be marked by low strategic information processing. Individuals' cognitive capacity to execute complex mental simulations, plan, or exhibit cognitive flexibility was thus not significantly related to their attitudes toward intergroup hierarchy or status quo biases. Recently it has been suggested that SDO (Sheehy-Skeffington \& Thomsen, 2020) and SJ (Goudarzi et al., 2020; Nam, 2020) may 
be biologically-grounded behavioural syndromes. Investigations with children suggest that preferences for egalitarianism and representations of social hierarchy emerge in infancy (Thomsen, 2020) and twin studies have suggested that SDO is moderately heritable (Kleppest $\varnothing$ et al., 2019). Theoretically, cognition constitutes the mediator between biological dispositions and political orientations (Ksiazkiewicz, Ludeke, \& Krueger, 2016; Oskarsson et al., 2014; Zmigrod, 2021) and so a critical question is what profile of cognitive traits is genetically transmitted in order to produce preferences for social hierarchies.

Some have posited that emotional tendencies, such as reduced empathic abilities and tendencies towards counter-empathy, may underpin people's preferences for hierarchy (Hudson, Cikara, \& Sidanius, 2019) and responses to inequality (Goudarzi, Pliskin, Jost, \& Knowles, 2020). Indeed, the amygdala - a brain structure implicated in emotional processing and affective flexibility in relation to motivational and environmental stimuli (Cunningham, Van Bavel, \& Johnsen, 2008) - has been consistently implicated in how humans understand and represent hierarchies (Kanai, Feilden, Firth, \& Rees, 2011; Kumaran, Melo, \& Duzel, 2012; Nam et al., 2018; Nam, 2020). Here, the personality signatures of SDO and SJ include heightened emotional control (Figure 10) and so perhaps excessive control over how empathy is experienced (i.e. towards whom) may be a core feature of insensitivity to inequality and injustice. Delineating the specific affective mechanisms that underpin SDO and SJ will help clarify the complex mechanisms linking these ideological worldviews with low-level cognitive and affective tendencies.

Ideological Extremism and Endorsement of Ideologically-Motivated Violence:

Ideological extremism can be separated into (at least) two interrelated tendencies: (a) extreme ideological identities, whereby individuals adopt an extreme partisan identity relative 
to moderates, and (b) the willingness to endorse violence and self-sacrifice in the name of an ideological group or cause. Both extreme ideological identities and endorsement of ideological violence have been implicated in mental inflexibility on visual and linguistic neuropsychological tasks (Table 2; Zmigrod et al., 2019; Schumann et al., 2021). Cognitive rigidity is evident in political extremism on both the political left and political right (Zmigrod, Rentfrow, \& Robbins, 2020) and when evaluating individuals' willingness to endorse ideological violence or self-sacrifice for the sake of an ideological group (Zmigrod et al., 2019; Zmigrod \& Goldenberg, 2021). Moreover, individuals who indicate in a hypothetical trolley problem scenario that they would opt to sacrifice their life in order to save members of their ideological group exhibited heightened cognitive rigidity (Schumann et al., 2021) as did individuals who indicated greater confidence in their choice to die for their ideological group (Zmigrod et al., 2019). Cognitive rigidity may thus be a susceptibility factor for ideological extremism (Zmigrod, 2021b).

More broadly, individuals who endorse ideologically-motivated violence performed more poorly on strategic information processing tasks involving in complex planning, mental simulations, working memory, and executive functions (Zmigrod et al., 2021). Extreme progroup attitudes were also related to greater caution in perceptual decision-making, operationalized in terms of a bias towards prioritizing accuracy over speed in tasks where both accuracy and speed are rewarded (Figure 11). As noted above, a cautious perceptual strategy has been implicated as a cognitive correlate of a majority of the political and religious ideologies, indicating it may broadly dispose individuals towards conservative mindsets. Examining the cognitive signature of extreme ideological identities on both the political right and the political left is therefore an essential empirical task for dissociating these ideological phenomena. 
Like patriotism (Figure 8) and engagement in religious practices such as prayer and service attendance (Figure 13), extreme pro-group attitudes were marked by a longer perceptual processing interval in perceptual decision-making tasks. Reaction times in cognitive tasks are the sum of decision time (time taken to form a decision in the task) and non-decision time (sensory delay and movement initiation). Non-decision perceptual processing time indexes the time taken by individuals to perceive the sensory information and initiate movement prior to making a decision. Hence, ideological extremists - along with patriots and those who frequently engage in religious prayer and practice - exhibit a significant sensory delay in basic cognitive tasks (Figure 11). Could sensory impairment heighten one's susceptibility to ideological practices that invite active participation, as extremism, patriotism, and religious involvement do? While empirical corroboration and theoretical details are necessary to clarify the reliability of these patterns and make stronger conclusions about causality, the relationships are intriguing and worth exploration.
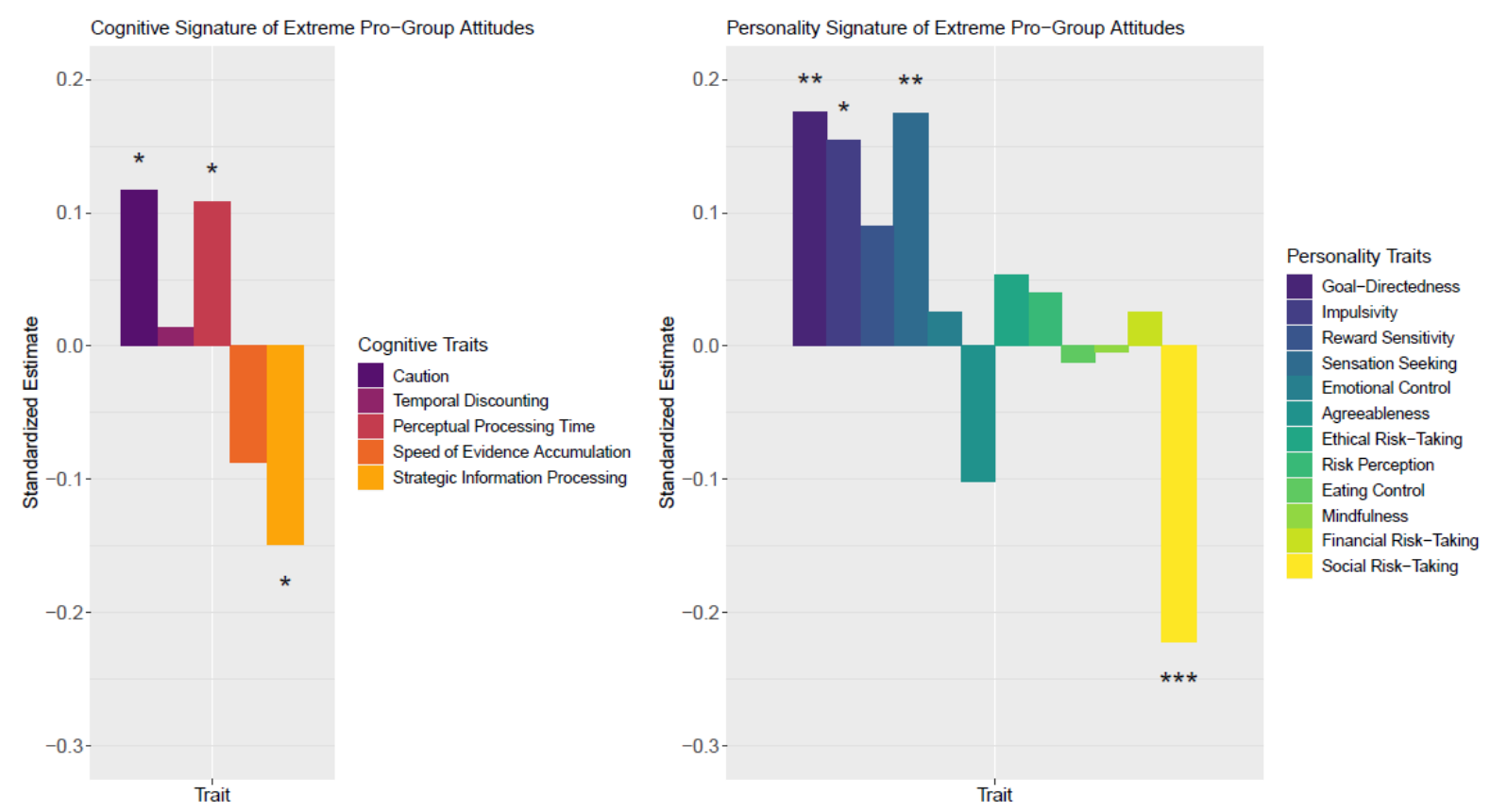

Figure 11. Individual-level cognitive and personality predictors of extreme pro-group attitudes. Bars reflect standardized beta estimates of multiple linear regression analyses. Adapted with permission from Zmigrod et al (2021). *p<.05, **p<.01, ***p<.001. 
From a personality perspective, extreme pro-group attitudes were linked to impulsivity and sensation-seeking, indicating that susceptible extremists may be particularly prone to emotion dysregulation and to seek emotionally intense experiences, such as participating in extreme ideological action (Zmigrod \& Goldenberg, 2021). As in all the conservative political ideologies, low social risk-taking and high goal-directedness were also features of extreme ideologues. Consequently, endorsement of ideological violence has its own unique cognitive and personality characteristics but also overlaps with other right-wing ideologies (Table 2).

\section{Religiosity:}

One of the hallmarks of religiosity, which distinguishes it from other traditional ideologies, is that it entails a belief in supernatural agents - agents which are believed to be omniscient monitors of inner psychic lives as well as externalized moral behaviour, with the capacity to reward, punish, and sometimes intervene in or forgive, human action or intention when it deviates from certain doctrinal expectations (Barrett, 2000; Boyer, 2001; Gervais \& Norenzayan, 2012; Norenzayan \& Shariff, 2008). Cognitive scientists of religion have posited that religious beliefs on supernatural agents partially reflect properties of human social cognition, such as mentalizing, mind reading, and teleology, that are applied to a non-human representation (Norenzayan \& Gervais, 2013). Religiosity thus encompasses a spectrum of beliefs and practices that range from the privately held to the publicly visible, such as engagement in private religious prayer, participation in public religious services and rituals, and valuing religion as an important guide to life. These features are fairly unique to religious ideologies, however can also emerge in political ideologies that have active social movements and demand regular or ritualistic participation (Zmigrod, 2022). At the same time, around the world, religion and political conservatism are often highly interlinked both psychologically (Friesen \& Ksiazkiewicz, 2015) and in terms of policy agendas (Layman, 1997), especially for those who are highly politically engaged (Malka, Lelkes, Srivastava, Cohen \& Miller, 2012). 
The cognitive and personality predictors of religiosity suggest both similarities and dissimilarities with those of political ideologies. Similarly to the signature of political conservatism, religiosity - as indexed by frequency of religious prayer, attendance at religious services, and importance of religious values - was marked by high perceptual caution and poorer performance on strategic information processing tasks (Figure 12; Zmigrod et al., 2021). Furthermore, like the politically conservative ideologies (Figure 6) and dogmatic mindsets (Table 1; Figure 3), religiosity was associated low social risk-taking in contexts that require non-conformity and disobedience. Similarly to social conservatism and patriotism, and unlike social dominance orientation or dogmatism, all the dimensions of religiosity were significantly associated with a more agreeable personality (Figures 12 and 13). This result corroborates. Saroglou's (2002) meta-analysis, which found that agreeableness was related to religiosity (weighted $\mathrm{r}=0.20,95 \% \mathrm{CI}[0.17,0.24]$ ) and to religious fundamentalism (weighted $\mathrm{r}=0.13$, $95 \%$ CI $[0.04,0.22])$.
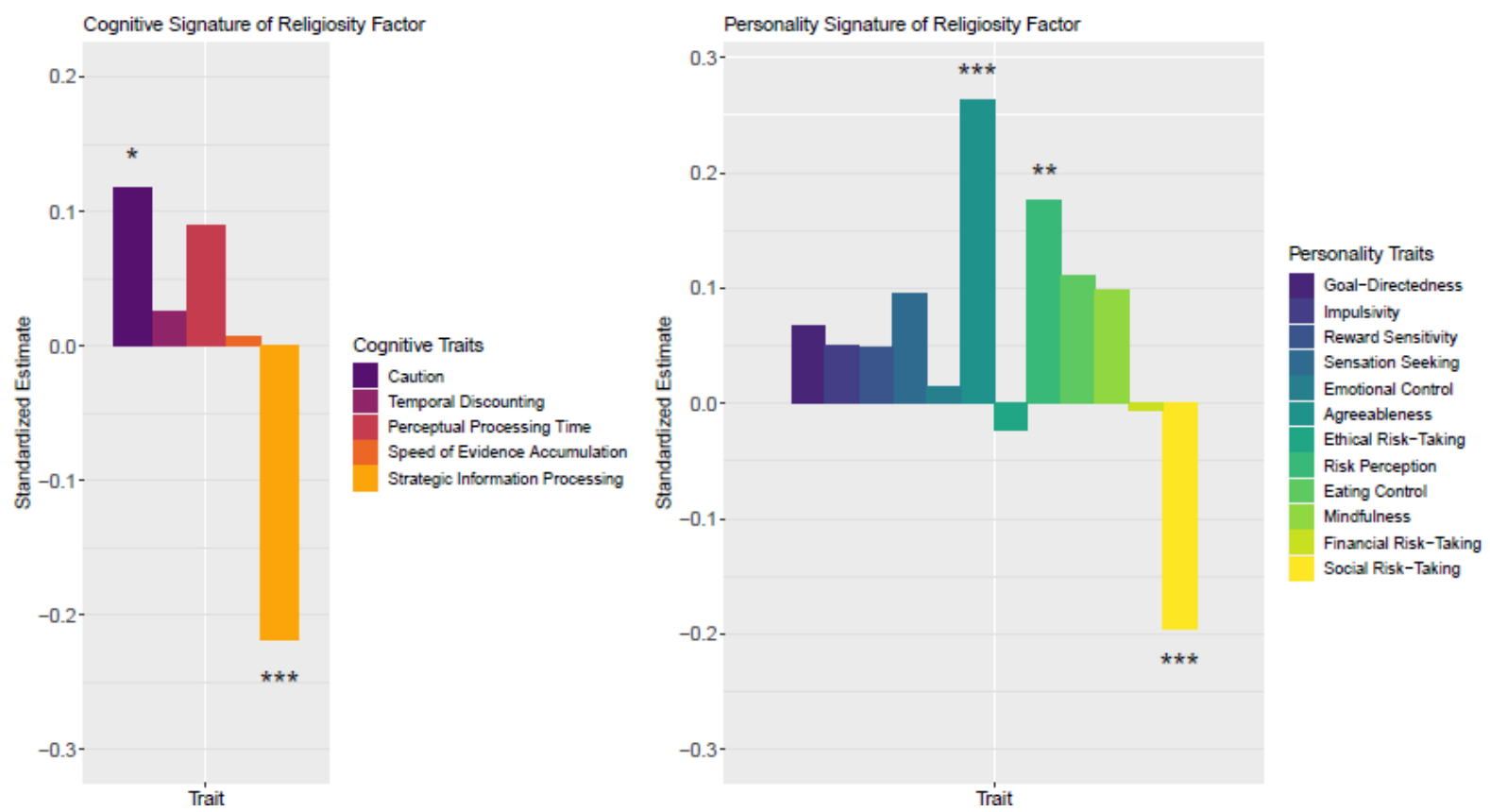

Figure 12. Individual-level cognitive and personality predictors of summative religiosity factor. Bars reflect standardized beta estimates of multiple linear regression analyses. Adapted with permission from Zmigrod et al (2021). *p<.05, **p<.01, ***p<.001. 
Moreover, a unique attribute of religiosity, evident in the summative religiosity factor (Figure 12) and pronounced in individuals who frequently pray (Figure 13B), is heightened risk perception. In other words, religious individuals tended to assess any risk-taking behaviour (in social, ethical, recreational, financial, and health domains; Blais \& Weber, 2006) as more inherently risky than non-religious individuals. This indicates that a heightened sensitivity to riskiness can confer susceptibility to religious thinking. Theoretically, this finding is concordant with theories that view religion as having an anxiety-reducing palliative effect (Inzlicht, Tullett, \& Good, 2011; Greenberg et al., 1997). However, it is noteworthy that the causal arrows may point in the other direction; participating in religious life and ritualistic prayer practices may heighten the perception of riskiness if there is a strong belief in an omniscient and judgmental god. Regardless of the causal direction, this relationship corroborates the central claim of the Neurocognitive Model of Ideological Thinking, which is that a pure emphasis on motivations is insufficient - ideologies shape and are shaped by domain-general cognitive dispositions (Zmigrod, 2021). Temporally-sensitive and longitudinal experimental designs are essential for disentangling the causal direction and identifying personenvironment interactions or self-reinforcing loops.

Additional nuances emerged from the psychological profile of religiosity. Notably, individuals who frequently attended public religious services and rituals - but not individuals who frequently prayed or valued religion highly - were highly sensation-seeking (Figure 13C; Zmigrod et al., 2021). Public displays of religiosity may therefore be partly motivated by a desire to feel intense emotional experiences - in the same way that sensation-seeking is a correlate of extreme pro-group attitudes (Figure 11). Ideological practices that involve action, such as endorsement of ideological violence or participation in religious services or prayer, may be satisfying some need for emotionally intense experiences. From a cognitive perspective, religious belief and frequency of participation in religious rituals are negatively 
associated with neuropsychologically-assessed cognitive flexibility (Zmigrod et al., 2019), suggesting that cognitive rigidity is not only implicated in susceptibility to extreme ideological action (Zmigrod \& Goldenberg, 2021) or political extremism (Zmigrod, Rentfrow, \& Robbins, 2020) but also engagement in religious practices. Sensation-seeking and rigidity could therefore be drivers of ideological engagement regardless of the content of the ideology (Zmigrod, 2022; Zmigrod \& Goldenberg, 2021).

Figure 13. Individual-level cognitive and personality predictors of $(A)$ importance of religion, (B), frequency of religious prayer, and (C) frequency of attendance at religious services. Bars reflect standardized beta estimates of multiple linear regression analyses. Adapted with permission from Zmigrod et al (2021). *p<.05, **p<.01, ***p<.001.
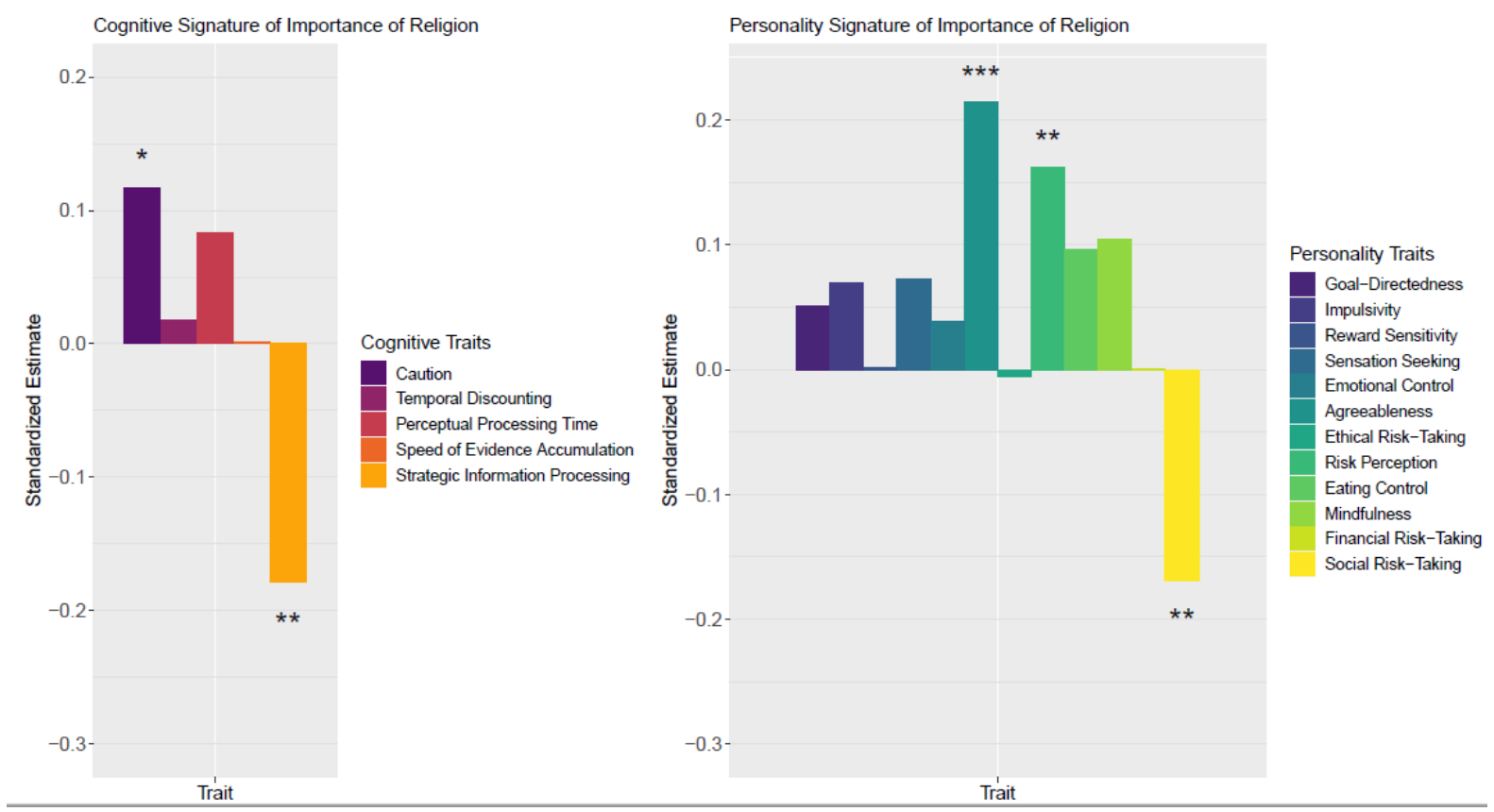

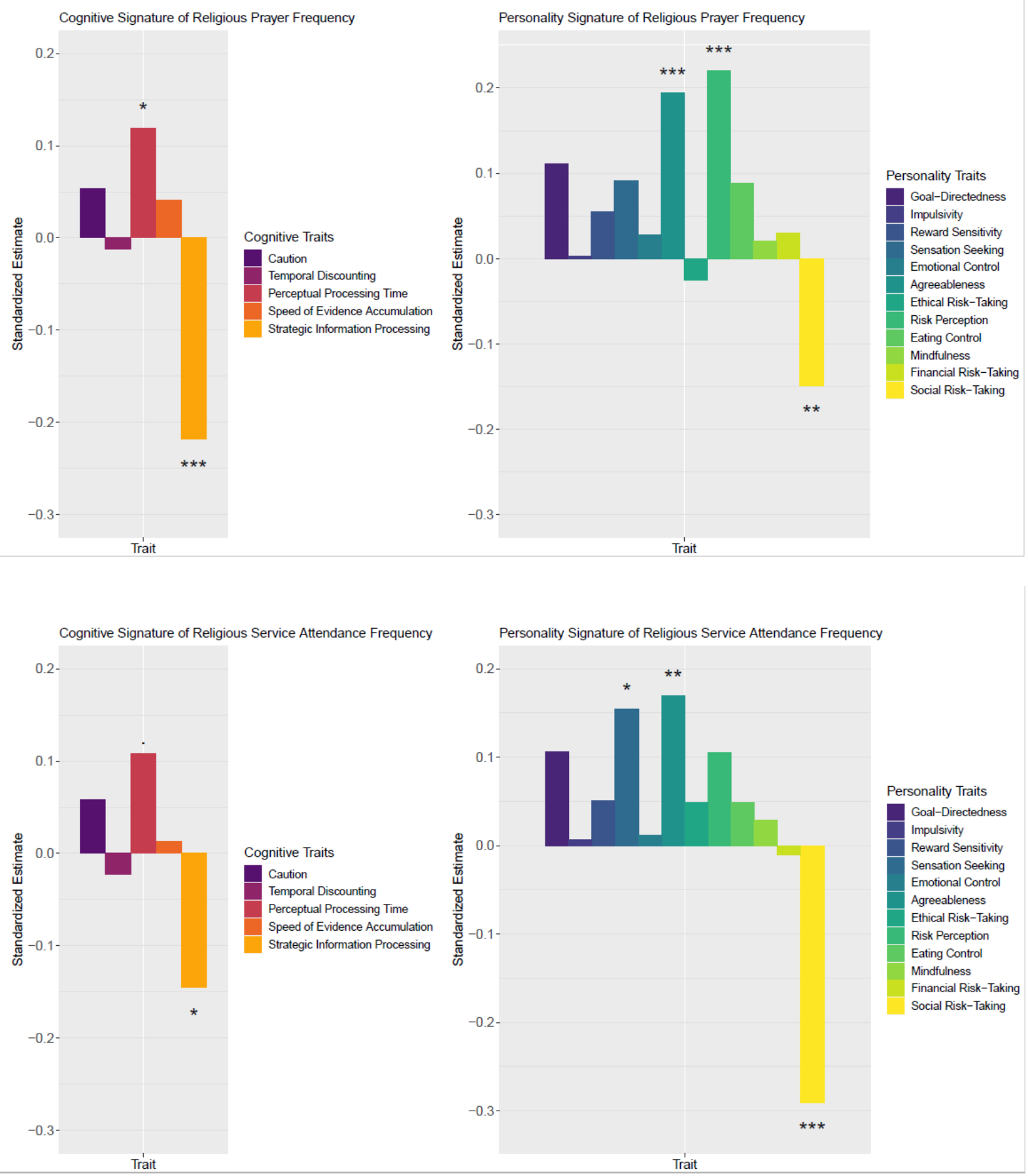

The Metaphors We Believe By: Bridging Perceptual Processes with Social

\section{Phenomena}

Theory-driven and data-driven approaches to ideological cognition have led to a fascinating insight: that individuals' cognitive and affective architecture mirrors their ideological beliefs. There are striking metaphors between cognition and ideology. Ideological 
rigidity is related to cognitive rigidity in neuropsychological tasks (Figure 2; Zmigrod, 2020; Zmigrod et al., 2018, 2019, 2020). Perceptual caution at the level of milliseconds is tied to ideological caution in politics and religion (Figures 6 and 12; Zmigrod et al., 2021). A tendency to make premature decisions based on imperfectly processed evidence in rapid perceptual decision-making tasks is linked to dogmatism and lack of intellectual humility (Figure 3; Zmigrod et al., 2021; Zmigrod \& Poldrack, in prep). A difficulty to process complex mental tasks is associated with an aversion to complexity in the socio-political realm (Figure 6; Table 2; Zmigrod \& Goldenberg, 2021). Perceiving risks in neutral everyday behaviours is associated with a greater reliance on religious ideologies which control and moralize risks (Figures 12 and 13). This is not tautology - the 'metaphors' between perception and ideology are remarkably domain-general (clear in both visual perception and ideological belief) and time-invariant (manifest on the order of milliseconds and timescales of days and lives).

One implication of these empirical findings is that the manner in which an individual forms and acts upon an ideological belief is fundamentally a reflection of how the individual forms and acts upon sensory beliefs. In other words, the mechanisms that govern low-level sensory belief formation may interact with the mechanisms that govern high-level ideological belief formation. Although outside the scope of the present review, it is noteworthy that recent advances in understanding the brain suggest that the metaphorical relations between cognition and ideology may be neuroanatomically plausible. An extensive neuroscientific literature has revealed that the brain, and especially the cortex, is organized hierarchically (Kiebel, Daunizeau, \& Friston, 2008) and that we can model how sensory beliefs propagate to higherorder goals and beliefs (Friston, 2010; Friston \& Frith, 2015; Friston et al., 2016, 2017). In short, if the brain is an organ constantly seeking to model and predict the causes and consequences of sensations and actions (as proposed by the free energy principle of brain function; Friston, 2010), then aberrations in how it models sensory evidence could plausibly 
propagate to how it models social and ideologically-relevant evidence (Zmigrod, in press). Consequently, it may be biologically plausible that individual differences in high-level ideological belief formation and maintenance reflect neurobiological idiosyncrasies already evident in the mechanisms governing low-level sensory belief formation.

Another insight from the empirical literature reviewed here is that, in contrast to intense debates in the field (Baron \& Jost; 2019; Ditto et al., 2019a, 2019b; Jost, 2017), dogmatism and political conservatism are cognitively orthogonal and dissociable. Cognitively, the profiles of dogmatic thinking and conservative or nationalistic of authoritarian thinking were completely distinct (Tables 1 and 2). Whereas dogmatic individuals were characterized by an impairment in sensory evidence accumulation, which indicated they were struggling to weave together sensory evidence in order to arrive at a rapid decision, conservatives and nationalists did not have an impairment in sensory evidence accumulation. Instead, political conservatism was associated with a perceptual preference for prioritizing accuracy over speed - a trade-off that is no better or worse than prioritizing speed over accuracy, given that both were rewarded in the behavioural tasks administered. Additionally, politically conservative ideologies were associated with an impairment in high-order executive function tasks, wherein dogmatic individuals performed as well as non-dogmatic individuals. The cognitive traits that yield dogmatism or political conservatism are therefore separable and unique. This pattern of results is not a commentary on the frequency with which dogmatism appears on the political left or the political right - it simply points out that the psychological traits of dogmatic or intellectually arrogant individuals are distinct from the psychological traits that are associated with conservatism. In other words, psychologists of ideologies need to be attuned to both ideological substance and structure, ideological content and ideological conviction, when modelling social behaviour. Indeed, the next frontier needs to address how these individualized psychological processes percolate into the realm of collective doctrines and social relations. 
Implicit in the direction of this burgeoning field lies the so-called 'chicken-and-egg problem' (Jost, Noorbaloochi, \& Van Bavel, 2014), that is, the problem of 'which comes first': psychological, perceptual, and physiological traits or ideological attitudes. In other words, do these neurocognitive dispositions shape which ideologies people find attractive, or do ideological environments shape adherents' neurocognitive processes? While the probable and natural answer is 'both', the future of the field hinges on whether we can clearly delineate the causal directions and possible interaction mechanisms implied by different experimental paradigms. In many instances, an exploration of the chicken-and-the-egg problem will reveal that the key moderating variable is in fact the nest - the social context and ecology (Zmigrod, in press).

The Neurocognitive Model of Ideological Thinking (Zmigrod, 2021) tries to formalize the bidirectional relationships between ideological phenomena and perceptual processes, appreciating that there are both bottom-up influences of neurocognitive dispositions on ideological orientations as well as top-down effects of immersion in ideological environments on cognition. The underlying implication behind this research program is that our political, religious, nationalistic, dogmatic, social worldviews matter not simply because they reflect who we are as individuals but because the consequences of ideologies have the potential to percolate to the most intimate ways in which we access information about the world, our senses. As Else Frenkel-Brunswik observed in 1952, "It is true that the authoritarian character in a certain sense is a mirror of his society. Yet at the same time he oversimplifies and distorts the social and cultural realities which have shaped him, as he distorts the perceptual ones. He reacts to some of the cliches rather than to the underlying complexities of our society. For this reason his adjustments function under narrowly circumscribed conditions only. He is not adapted to change and thus lacks one of the most important requirements in all modern societies" (p. 64). Addressing the relationships between ideological phenomena and perceptual processes is thus 
a scientific as well as a political matter - allowing us to elucidate how and why ideologies captivate the human brain, and what this means for our social and political existences. 


\section{References}

Adorno, T. W., Frenkel-Brunswik, E., Levinson, D. J., \& Sanford, R. N. (1950). The Authoritarian Personality. New York: Harper.

Allport, G. W. (1954). The nature of prejudice. Addison-Wesley.

Arendt, H. (1951). The origins of totalitarianism. Meridian.

Asch, S. E. (1956). Studies of independence and conformity: I. A minority of one against a unanimous majority. Psychological monographs: General and applied, 70(9), 1.

Azevedo, F., \& Jost, J. T. (2021). The ideological basis of antiscientific attitudes: Effects of authoritarianism, conservatism, religiosity, social dominance, and system justification. Group Processes \& Intergroup Relations, 24(4), 518-549.

Bakker, B. N., Schumacher, G., Gothreau, C., \& Arceneaux, K. (2020). Conservatives and liberals have similar physiological responses to threats. Nature Human Behaviour, 4(6), 613621.

Baron, J., \& Jost, J. T. (2019). False equivalence: Are liberals and conservatives in the United States equally biased?. Perspectives on Psychological Science, 14(2), 292-303.

Barrett, J. L. (2000). Exploring the natural foundations of religion. Trends in cognitive sciences, 4(1), 29-34.

Bernardo, F. (2013). Impact of place attachment on risk perception: Exploring the multidimensionality of risk and its magnitude. Estudios de Psicología, 34(3), 323-329.

Billig, M. (2006). Is my home my castle? Place attachment, risk perception, and religious faith. Environment and behavior, 38(2), 248-265. 
Blais, A. R., \& Weber, E. U. (2006). A Domain-Specific Risk-Taking (DOSPERT) scale for adult populations. Judgment and Decision Making, 1, 33-47.

Burger, A. M., Pfattheicher, S., \& Jauch, M. (2020). The role of motivation in the association of political ideology with cognitive performance. Cognition, 195, 104124.

Campbell, A., Converse, P., Miller, W., \& Stokes, D. (1960). The American voter. John Wiley \& Sons.

Carmines, E. G., \& D'Amico, N. J. (2015). The new look in political ideology research. Annual Review of Political Science, 18, 205-216.

Cichocka, A., Dhont, K., Makwana, A. P., \& Back, M. (2017). On self-love and outgroup hate: Opposite effects of narcissism on prejudice via social dominance orientation and right-wing authoritarianism. European Journal of Personality, 31(4), 366-384.

Crawford, J. T., \& Pilanski, J. M. (2014). Political intolerance, right and left. Political Psychology, 35(6), 841-851.

Crowson, H. M. (2009). Are all conservatives alike? A study of the psychological correlates of cultural and economic conservatism. The Journal of psychology, 143(5), 449-463.

De Dreu, C. K., Pliskin, R., Rojek-Giffin, M., Méder, Z., \& Gross, J. (2021). Political games of attack and defence. Philosophical Transactions of the Royal Society B, 376(1822), 20200135.

Dember, W. N. (1974). Motivation and the cognitive revolution. American Psychologist, 29(3), 161-168. https://doi.org/10.1037/h0035907

Dhont, K., \& Hodson, G. (2014). Does lower cognitive ability predict greater prejudice?. Current Directions in Psychological Science, 23(6), 454-459. 
Ditto, P. H., Liu, B. S., Clark, C. J., Wojcik, S. P., Chen, E. E., Grady, R. H., ... \& Zinger, J. F. (2019a). At least bias is bipartisan: A meta-analytic comparison of partisan bias in liberals and conservatives. Perspectives on Psychological Science, 14(2), 273-291.

Ditto, P. H., Clark, C. J., Liu, B. S., Wojcik, S. P., Chen, E. E., Grady, R. H., ... \& Zinger, J. F. (2019b). Partisan bias and its discontents. Perspectives on Psychological Science, 14(2), 304316.

Duckitt, J., \& Sibley, C. G. (2009). A dual-process motivational model of ideology, politics, and prejudice. Psychological Inquiry, 20(2-3), 98-109.

Dodd, M. D., Balzer, A., Jacobs, C. M., Gruszczynski, M. W., Smith, K. B., \& Hibbing, J. R. (2012). The political left rolls with the good and the political right confronts the bad: connecting physiology and cognition to preferences. Philosophical Transactions of the Royal Society B: Biological Sciences, 367(1589), 640-649.

Duckitt, J., \& Sibley, C. G. (2010). Personality, ideology, prejudice, and politics: A dualprocess motivational model. Journal of personality, 78(6), 1861-1894.

Eisenberg, I. W., Bissett, P. G., Canning, J. R., Dallery, J., Enkavi, A. Z., Whitfield-Gabrieli, S., .. \& Poldrack, R. A. (2018). Applying novel technologies and methods to inform the ontology of self-regulation. Behaviour research and therapy, 101, 46-57.

Eisenberg, I. W., Bissett, P. G., Enkavi, A. Z., Li, J., MacKinnon, D. P., Marsch, L. A., \& Poldrack, R. A. (2019). Uncovering the structure of self-regulation through data-driven ontology discovery. Nature communications, 10(1), 1-13.

Enkavi, A. Z., Eisenberg, I. W., Bissett, P. G., Mazza, G. L., MacKinnon, D. P., Marsch, L. A., \& Poldrack, R. A. (2019). Large-scale analysis of test-retest reliabilities of self-regulation measures. Proceedings of the National Academy of Sciences, 116(12), 5472-5477. 
Everett, J. A. (2013). The 12 item social and economic conservatism scale (SECS). PloS one, $8(12), \mathrm{e} 82131$.

Federico, C. M., Golec, A., \& Dial, J. L. (2005). The relationship between the need for closure and support for military action against Iraq: Moderating effects of national attachment. Personality and Social Psychology Bulletin, 31(5), 621-632.

Festinger, L., Riecken, H. W., \& Schachter, S. (1956). When prophecy fails. University of Minnesota Press. https://doi.org/10.1037/10030-000

Frenkel-Brunswik, E. (1948). A study of prejudice in children. Human relations, 1(3), 295306.

Frenkel-Brunswik, E. (1949). Intolerance of ambiguity as an emotional and perceptual personality variable. Journal of personality.

Frenkel-Brunswik, E. (1952). Interaction of psychological and sociological factors in political behavior. American Political Science Review, 46(1), 44-65.

Friedkin, N. E., Proskurnikov, A. V., Tempo, R., \& Parsegov, S. E. (2016). Network science on belief system dynamics under logic constraints. Science, 354(6310), 321-326.

Friesen, A., \& Ksiazkiewicz, A. (2015). Do political attitudes and religiosity share a genetic path?. Political Behavior, 37(4), 791-818.

Friston, K. (2010). The free-energy principle: a unified brain theory?. Nature reviews neuroscience, 11(2), 127-138.

Friston, K., FitzGerald, T., Rigoli, F., Schwartenbeck, P., \& Pezzulo, G. (2016). Active inference and learning. Neuroscience \& Biobehavioral Reviews, 68, 862-879. 
Friston, K., FitzGerald, T., Rigoli, F., Schwartenbeck, P., \& Pezzulo, G. (2017). Active inference: a process theory. Neural computation, 29(1), 1-49.

Friston, K. J., \& Frith, C. D. (2015). Active inference, communication and hermeneutics. cortex, 68, 129-143.

Inzlicht, M., Tullett, A. M., \& Good, M. (2011). The need to believe: a neuroscience account of religion as a motivated process. Religion, brain \& behavior, 1(3), 192-212.

Gervais, W. M., \& Norenzayan, A. (2012). Like a camera in the sky? Thinking about God increases public self-awareness and socially desirable responding. Journal of experimental social psychology, 48(1), 298-302.

Greenberg, J., Solomon, S., \& Pyszczynski, T. (1997). Terror management theory of selfesteem and cultural worldviews: Empirical assessments and conceptual refinements. Advances in experimental social psychology, 29, 61-139.

Halevy, Y. (2008). Strotz meets Allais: Diminishing impatience and the certainty effect. American Economic Review, 98(3), 1145-62.

Harris, E. A., \& Van Bavel, J. J. (2021). Preregistered Replication of "Feeling superior is a bipartisan issue: Extremity (not direction) of political views predicts perceived belief superiority”. Psychological Science, 32(3), 451-458.

Heaven, P. C., Ciarrochi, J., \& Leeson, P. (2011). Cognitive ability, right-wing authoritarianism, and social dominance orientation: A five-year longitudinal study amongst adolescents. Intelligence, 39(1), 15-21.

Hetherington, M. J., \& Weiler, J. D. (2009). Authoritarianism and polarization in American politics. Cambridge University Press. 
Hibbing, J. R., Smith, K. B., \& Alford, J. R. (2014). Differences in negativity bias underlie variations in political ideology. Behavioral and brain sciences, 37, 297-307.

Hodson, G., \& Busseri, M. A. (2012). Bright minds and dark attitudes: Lower cognitive ability predicts greater prejudice through right-wing ideology and low intergroup contact. Psychological science, 23(2), 187-195.

Hodson, G., \& Dhont, K. (2015). The person-based nature of prejudice: Individual difference predictors of intergroup negativity. European Review of Social Psychology, 26(1), 1-42.

Huddy, L., \& Feldman, S. (2011). Americans respond politically to 9/11: Understanding the impact of the terrorist attacks and their aftermath. American Psychologist, 66(6), 455467. https://doi.org/10.1037/a0024894

Huddy, L., \& Khatib, N. (2007). American patriotism, national identity, and political involvement. American journal of political science, 51(1), 63-77.

Hudson, S. K. T. J., Cikara, M., \& Sidanius, J. (2019). Preference for hierarchy is associated with reduced empathy and increased counter-empathy towards others, especially out-group targets. Journal of Experimental Social Psychology, 85, 103871.

Hyman, H. (1959). Political socialization. Free Press.

Inzlicht, M., McGregor, I., Hirsh, J. B., \& Nash, K. (2009). Neural markers of religious conviction. Psychological science, 20(3), 385-392.

Inzlicht, M., Tullett, A. M., \& Good, M. (2011). The need to believe: a neuroscience account of religion as a motivated process. Religion, brain \& behavior, 1(3), 192-212.

Janoff-Bulman, R. (2009). To provide or protect: Motivational bases of political liberalism and conservatism. Psychological Inquiry, 20(2-3), 120-128. 
Jarvinen, M. J., \& Paulus, T. B. (2017). Attachment and cognitive openness: Emotional underpinnings of intellectual humility. The Journal of Positive Psychology, 12(1), 74-86.

Jedinger, A., \& Burger, A. M. (2020). The ideological foundations of economic protectionism: Authoritarianism, social dominance orientation, and the moderating role of political involvement. Political Psychology, 41(2), 403-424.

Johnson, S. D., \& Tamney, J. B. (2001). Social traditionalism and economic conservatism: Two conservative political ideologies in the United States. The Journal of social psychology, 141(2), 233-243.

Jost, J. T. (2006). The end of the end of ideology. American psychologist, 61(7), 651.

Jost, J. T. (2017). Ideological asymmetries and the essence of political psychology. Political psychology, 38(2), 167-208.

Jost, J. T., Badaan, V., Goudarzi, S., Hoffarth, M., \& Mogami, M. (2019). The future of system justification theory. British Journal of Social Psychology, 58(2), 382-392.

Jost, J. T., Napier, J. L., Thorisdottir, H., Gosling, S. D., Palfai, T. P., \& Ostafin, B. (2007). Are needs to manage uncertainty and threat associated with political conservatism or ideological extremity?. Personality and social psychology bulletin, 33(7), 989-1007.

Jost, J. T., Noorbaloochi, S., \& Van Bavel, J. J. (2014). The" chicken-and-egg" problem in political neuroscience. Behavioral and Brain Sciences, 37(3), 317.

Kahle, L. R. (1984). Attitudes and social adaptation: A person-situation interaction approach. Pergamon Press.

Kalmoe, N. P. (2020). Uses and abuses of ideology in political psychology. Political Psychology, 41(4), 771-793. 
Kashima, Y., Perfors, A., Ferdinand, V., \& Pattenden, E. (2021). Ideology, communication and polarization. Philosophical Transactions of the Royal Society B, 376(1822), 20200133.

Kay, A. C., \& Jost, J. T. (2003). Complementary justice: effects of" poor but happy" and" poor but honest" stereotype exemplars on system justification and implicit activation of the justice motive. Journal of personality and social psychology, 85(5), 823.

Keren, G., \& Roelofsma, P. (1995). Immediacy and certainty in intertemporal choice. Organizational Behavior and Human Decision Processes, 63(3), 287-297.

Kiebel, S. J., Daunizeau, J., \& Friston, K. J. (2008). A hierarchy of time-scales and the brain. PLoS computational biology, 4(11), e1000209.

Kleck, R. E., \& Wheaton, J. (1967). Dogmatism and responses to opinion-consistent and opinion-inconsistent information. Journal of personality and social psychology, 5(2), 249.

Kleppestø, T. H., Czajkowski, N. O., Vassend, O., Røysamb, E., Eftedal, N. H., SheehySkeffington, J., ... \& Thomsen, L. (2019). Correlations between social dominance orientation and political attitudes reflect common genetic underpinnings. Proceedings of the National Academy of Sciences, 116(36), 17741-17746.

Knoll, B. R., O’Daniel, T. J., \& Cusato, B. (2015). Physiological responses and political behavior: Three reproductions using a novel dataset. Research \& Politics, 2(4), 2053168015621328.

Krumrei-Mancuso, E. J., \& Newman, B. (2020). Intellectual humility in the sociopolitical domain. Self and Identity, 19(8), 989-1016.

Krumrei-Mancuso, E. J., \& Rouse, S. V. (2016). The development and validation of the comprehensive intellectual humility scale. Journal of Personality Assessment, 98(2), 209-221. 
Ksiazkiewicz, A., Ludeke, S., \& Krueger, R. (2016). The role of cognitive style in the link between genes and political ideology. Political Psychology, 37(6), 761-776.

Kumaran, D., Melo, H. L., \& Duzel, E. (2012). The emergence and representation of knowledge about social and nonsocial hierarchies. Neuron, 76(3), 653-666.

Layman, G. C. (1997). Religion and political behavior in the United States: The impact of beliefs, affiliations, and commitment from 1980 to 1994. Public Opinion Quarterly, 288-316.

Leary, M. R., Diebels, K. J., Davisson, E. K., Jongman-Sereno, K. P., Isherwood, J. C., Raimi, K. T., ... \& Hoyle, R. H. (2017). Cognitive and interpersonal features of intellectual humility. Personality and Social Psychology Bulletin, 43(6), 793-813.

Malka, A., Lelkes, Y., Srivastava, S., Cohen, A. B., \& Miller, D. T. (2012). The association of religiosity and political conservatism: The role of political engagement. Political Psychology, 33(2), 275-299.

Malka, A., Soto, C. J., Inzlicht, M., \& Lelkes, Y. (2014). Do needs for security and certainty predict cultural and economic conservatism? A cross-national analysis. Journal of Personality and Social Psychology, 106(6), 1031-1051. https://doi.org/10.1037/a0036170

Milgram, S. (1963). Behavioral study of obedience. The Journal of abnormal and social psychology, 67(4), 371.

Molden, D. C., Bayes, R., \& Druckman, J. N. (2021). A motivational systems approach to investigating opinions on climate change. Thinking \& Reasoning, 1-32.

Nam, H. H. (2020). Neuroscientific approaches to the study of system justification. Current Opinion in Behavioral Sciences, 34, 205-210.

Norenzayan, A., \& Gervais, W. M. (2013). The origins of religious disbelief. Trends in cognitive sciences, 17(1), 20-25. 
Onraet, E., Van Hiel, A., Dhont, K., Hodson, G., Schittekatte, M., \& De Pauw, S. (2015). The association of cognitive ability with right-wing ideological attitudes and prejudice: A metaanalytic review. European Journal of Personality, 29(6), 599-621.

Oskarsson, S., Cesarini, D., Dawes, C. T., Fowler, J. H., Johannesson, M., Magnusson, P. K., \& Teorell, J. (2015). Linking genes and political orientations: Testing the cognitive ability as mediator hypothesis. Political Psychology, 36(6), 649-665.

Osmundsen, M., Hendry, D., Laustsen, L., Smith, K., \& Petersen, M. B. (2021). The psychophysiology of political ideology: Replications, reanalysis and recommendations. Journal of Politics. https://doi.org/10.1086/714780

Paglieri, F., Borghi, A. M., Colzato, L. S., Hommel, B., \& Scorolli, C. (2013). Heaven can wait. How religion modulates temporal discounting. Psychological research, 77(6), 738-747.

Palmer, D. L. , \& Klain , R. ( 1985 ). Dogmatic responses to belief dissimilarity in the "bogus stranger" paradigm. Journal of Personality and Social Psychology , 48 , 171 - 179.

Parsegov, S. E., Proskurnikov, A. V., Tempo, R., \& Friedkin, N. E. (2016). Novel multidimensional models of opinion dynamics in social networks. IEEE Transactions on Automatic Control, 62(5), 2270-2285.

Porter, T., \& Schumann, K. (2018). Intellectual humility and openness to the opposing view. Self and Identity, 17(2), 139-162.

Pratto, F., Çidam, A., Stewart, A. L., Zeineddine, F. B., Aranda, M., Aiello, A., ... \& Henkel, K. E. (2013). Social dominance in context and in individuals: Contextual moderation of robust effects of social dominance orientation in 15 languages and 20 countries. Social Psychological and Personality Science, 4(5), 587-599. 
Reinero, D. A., Wills, J. A., Brady, W. J., Mende-Siedlecki, P., Crawford, J. T., \& Van Bavel, J. J. (2020). Is the political slant of psychology research related to scientific replicability?. Perspectives on Psychological Science, 15(6), 1310-1328.

Rokeach, M. (1960). The open and closed mind. New York: Basic Books

Rollwage, M., Zmigrod, L., de-Wit, L., Dolan, R. J., \& Fleming, S. M. (2019). What underlies political polarization? A manifesto for computational political psychology. Trends in cognitive sciences, 23(10), 820-822.

Saroglou, V. (2002). Religion and the five factors of personality: A meta-analytic review. Personality and individual differences, 32(1), 15-25.

Saunders, B., Milyavskaya, M., Etz, A., Randles, D., Inzlicht, M., \& Vazire, S. (2018). Reported self-control is not meaningfully associated with inhibition-related executive function: A Bayesian analysis. Collabra: Psychology, 4(1).

Schumann, S., Salman, N. L., Clemmow, C., \& Gill, P. (2021). Does cognitive inflexibility predict violent extremist behaviour intentions? A registered direct replication report of Zmigrod, Rentfrow, \& Robbins, 2019. Legal and Criminological Psychology, 26(2), 145-157.

Shearman, S. M., \& Levine, T. R. (2006). Dogmatism updated: A scale revision and validation. Communication Quarterly, 54(3), 275-291.

Sheehy-Skeffington, J., \& Thomsen, L. (2020). Egalitarianism: psychological and socioecological foundations. Current opinion in psychology, 32, 146-152.

Sheikh, H., Ginges, J., \& Atran, S. (2013). Sacred values in the Israeli-Palestinian conflict: resistance to social influence, temporal discounting, and exit strategies. Annals of the New York Academy of Sciences, 1299(1), 11-24. 
Shenhav, A., Rand, D. G., \& Greene, J. D. (2017). The relationship between intertemporal choice and following the path of least resistance across choices, preferences, and beliefs. Judgment and Decision Making, 12(1), 1-18.

Sherif, M. (1936). The psychology of social norms. Harper: New York.

Sibley, C. G., \& Duckitt, J. (2008). Personality and prejudice: A meta-analysis and theoretical review. Personality and Social Psychology Review, 12(3), 248-279.

Sidanius, J., Feshbach, S., Levin, S., \& Pratto, F. (1997). The interface between ethnic and national attachment: Ethnic pluralism or ethnic dominance?. The Public Opinion Quarterly, 61(1), 102-133.

Smith, K. B., \& Warren, C. (2020). Physiology predicts ideology. Or does it? The current state of political psychophysiology research. Current Opinion in Behavioral Sciences, 34, 88-93.

Smith, K. B., Oxley, D., Hibbing, M. V., Alford, J. R., \& Hibbing, J. R. (2011). Disgust sensitivity and the neurophysiology of left-right political orientations. PloS one, 6(10), e25552.

Stanley, S. K., Milfont, T. L., Wilson, M. S., \& Sibley, C. G. (2019). The influence of social dominance orientation and right-wing authoritarianism on environmentalism: A five-year cross-lagged analysis. Plos one, 14(7), e0219067.

Stanley, S. K., Wilson, M. S., \& Milfont, T. L. (2017). Exploring short-term longitudinal effects of right-wing authoritarianism and social dominance orientation on environmentalism. Personality and Individual Differences, 108, 174-177.

Swann Jr, W. B., Gómez, A., Seyle, D. C., Morales, J., \& Huici, C. (2009). Identity fusion: the interplay of personal and social identities in extreme group behavior. Journal of personality and social psychology, 96(5), 995. 
Thomsen, L. (2020). The developmental origins of social hierarchy: How infants and young children mentally represent and respond to power and status. Current opinion in psychology, 33, 201-208.

Toner, K., Leary, M. R., Asher, M. W., \& Jongman-Sereno, K. P. (2013). Feeling superior is a bipartisan issue: Extremity (not direction) of political views predicts perceived belief superiority. Psychological Science, 24(12), 2454-2462.

Van Bavel, J. J., \& Pereira, A. (2018). The partisan brain: An identity-based model of political belief. Trends in cognitive sciences, 22(3), 213-224.

Van Hiel, A., Onraet, E., Crowson, H. M., \& Roets, A. (2016). The Relationship between Right-wing Attitudes and Cognitive Style: A Comparison of Self-report and Behavioural Measures of Rigidity and Intolerance of Ambiguity. European Journal of Personality, 30(6), $523-531$.

Vargas-Salfate, S., Paez, D., Liu, J. H., Pratto, F., \& Gil de Zúñiga, H. (2018). A comparison of social dominance theory and system justification: The role of social status in 19 nations. Personality and Social Psychology Bulletin, 44(7), 1060-1076.

Walker, S. G. (1983). The motivational foundations of political belief systems: A re-analysis of the operational code construct. International Studies Quarterly, 27(2), 179-202.

Washburn, A. N., \& Skitka, L. J. (2018). Strategies for promoting strong inferences in political psychology research. In Belief systems and the perception of reality (pp. 134-146). Routledge.

Webber, D., \& Kruglanski, A. W. (2018). The social psychological makings of a terrorist. Current opinion in psychology, 19, 131-134.

Wennerhold, L., Friese, M., \& Vazire, S. (2020). Why self-report measures of self-control and inhibition tasks do not substantially correlate. Collabra: Psychology, 6(1). 
Yilmaz, O., \& Saribayf, S. A. (2017). The relationship between cognitive style and political orientation depends on the measures used. Judgment and Decision Making, 12(2), 140-148.

Zaller, J. (1992). The nature and origins of mass opinion. Cambridge University Press.

Zmigrod, L. (2020). The role of cognitive rigidity in political ideologies: theory, evidence, and future directions. Current Opinion in Behavioral Sciences, 34, 34-39.

Zmigrod, L. (2021). A neurocognitive model of ideological thinking. Politics and the Life Sciences, 40(2), 224-238.

Zmigrod, L. (2022). A Psychology of Ideology: Unpacking the Psychological Structure of Ideological Thinking. Perspectives on Psychological Science. doi:10.1177/17456916211044140.

Zmigrod, L. (in press). Mental Computations of Ideological Choice and Conviction: The Utility of Integrating Psycho-Economics and Bayesian Models of Belief. Psychological Inquiry.

Zmigrod, L., Ebert, T., Götz, F. M., \& Rentfrow, P. J. (2021). The Psychological and SocioPolitical Consequences of Infectious Diseases: Authoritarianism, Governance, and Nonzoonotic (Human-to-Human) Infection Transmission. Journal of Social and Political Psychology, 9(2), 456-474.

Zmigrod, L., Eisenberg, I. W., Bissett, P. G., Robbins, T. W., \& Poldrack, R. A. (2021). The cognitive and perceptual correlates of ideological attitudes: a data-driven approach. Philosophical Transactions of the Royal Society B, 376(1822), 20200424.

Zmigrod, L., \& Goldenberg, A. (2021). Cognition and Emotion in Extreme Political Action: Individual Dispositions and Dynamic Interactions. Current Directions in Psychological Science. 
Zmigrod, L., \& Poldrack, R. A. (in prep). Dogmatism is Linked to Impaired Perceptual Evidence Processing: Computational Analysis of 14 Cognitive Tasks.

Zmigrod, L., Rentfrow, P. J., \& Robbins, T. W. (2018). Cognitive underpinnings of nationalistic ideology in the context of Brexit. Proceedings of the National Academy of Sciences, 115(19), E4532-E4540.

Zmigrod, L., Rentfrow, P. J., \& Robbins, T. W. (2019). Cognitive inflexibility predicts extremist attitudes. Frontiers in psychology, 10, 989.

Zmigrod, L., Rentfrow, P. J., \& Robbins, T. W. (2020). The partisan mind: Is extreme political partisanship related to cognitive inflexibility?. Journal of Experimental Psychology: General, 149(3), 407.

Zmigrod, L., Rentfrow, P. J., Zmigrod, S., \& Robbins, T. W. (2019). Cognitive flexibility and religious disbelief. Psychological research, 83(8), 1749-1759.

Zmigrod, L. \& Tsakiris, M. (2021). Computational and Neurocognitive Approaches to the Political Brain: Key Insights and Future Avenues for Political Neuroscience. Philosophical Transactions of the Royal Society B: Biological Sciences. 20200130.

Zmigrod, L., Zmigrod, S., Rentfrow, P. J., \& Robbins, T. W. (2019). The psychological roots of intellectual humility: The role of intelligence and cognitive flexibility. Personality and Individual Differences, 141, 200-208. 